\title{
A NEW STRATEGY FOR THE DECELLULARISATION OF LARGE EQUINE TENDONS AS BIOCOMPATIBLE TENDON SUBSTITUTES
}

\author{
M. Bottagisio ${ }^{1}$, A.F. Pellegata ${ }^{2}$, F. Boschetti ${ }^{2}$, M. Ferroni ${ }^{2}$, M. Moretti ${ }^{1,3,4,5}$ and A.B. Lovati ${ }^{1 *}$ \\ ${ }^{1}$ Cell and Tissue Engineering Laboratory, IRCCS Galeazzi Orthopaedic Institute, Milan, Italy \\ ${ }^{2}$ Department of Chemistry, Materials and Chemical Engineering Giulio Natta, Politecnico di Milano, Milan, Italy \\ ${ }^{3}$ Regenerative Medicine Technologies Lab, Ente Ospedaliero Cantonale (EOC), Lugano, Switzerland \\ ${ }^{4}$ Swiss Institute of Regenerative Medicine (SIRM), Lugano, Switzerland \\ ${ }^{5}$ Fondazione Cardiocentro Ticino, Lugano, Switzerland
}

\begin{abstract}
Tendon ruptures and/or large losses remain to be a great clinical challenge and often require full replacement of the damaged tissue. The use of auto- and allografts or engineered scaffolds is an established approach to restore severe tendon injuries. However, these grafts are commonly related to scarce biocompatibility, site morbidity, chronic inflammation and poor biomechanical properties. Recently, the decellularisation techniques of allo- or xenografts using specific detergents have been studied and have been found to generate biocompatible substitutes that resemble the native tissue.

This study aims to identify a novel decellularisation protocol for large equine tendons that would produce an extracellular matrix scaffold suitable for the regeneration of injured tendons in humans. Specifically, equine tendons were treated either with tri (n-butyl) phosphate alone, or associated to multiple concentrations of peracetic acid (1, 3 and $5 \%$ ), which has never before been tested in vitro. Samples were then analysed by histology and with biochemical, biomechanical, and cytotoxicity tests. The best decellularisation protocol, resulting from these examinations, was selected and the chosen scaffold was re-seeded with murine fibroblasts. Resulting grafts were tested for cell viability, histologic analysis, DNA and collagen content. The results identified $1 \%$ tri (n-butyl) phosphate combined with $3 \%$ peracetic acid as the most suitable decellularised matrix in terms of biochemical and biomechanical properties. Moreover, the non-cytotoxic nature of the decellularised matrix allowed for good fibroblast reseeding, thus demonstrating a biocompatible matrix that will be suitable for tendon tissue engineering and hopefully as substitutes in severe tendon damages.
\end{abstract}

Keywords: Xenograft, equine tendon, decellularisation, biomaterials, biomechanics, cell adhesion.

*Address for correspondence:

Arianna Barbara Lovati

Cell and Tissue Engineering Laboratory

IRCCS Galeazzi Orthopaedic Institute

via R. Galeazzi 4

20161 Milan, Italy

Telephone number: +390266214069

Fax number: +390266214060

Email: arianna.lovati@grupposandonato.it

\section{Introduction}

Traumatic acute events leading to tendon losses, as well as ruptures related to degenerative tendinopathy, require a replacement of the damaged tissue. In particular, the incidence of acute events occurring in the flexor and extensor tendons of the hand is close to 4.83 and $18 / 100.000$ cases per year, respectively. Similarly, Achilles tendon ruptures occur in 12-18/100.000 per year, and rotator cuff tendon lesions in 3.73/100.000 cases per year (Shearn et al., 2011; Clayton and Court-Brown, 2008). Yet, in these cases, the healing process does not efficiently restore the native tendon structure and function, despite the surgical intervention, with a high rate of re-tear (Sharma and Maffulli, 2006; Andarawis-Puri et al., 2015). Nowadays, tendon autografts are the common choice for the reconstruction of tendon integrity (Yao et al., 2015), despite their limited supply, high donor-site morbidity, and poor functional outcomes (Gazdag et al., 1995; Lovati et al., 2016). To overcome these limitations, the field of tissue engineering widely investigated the generation of cell-seeded scaffolds to promote regeneration and implanttissue integration (Kuo et al., 2010; Shearn et al., 2011). An ideal bioengineered tendon graft should be biocompatible, support cell attachment and host integration, and have biochemical and mechanical properties similar to the native tendon. However, synthetic scaffolds were not able to satisfy mechanical and structural properties (Zhang and Chang, 2003), and result in poor functional outcomes (Garvin et al., 2003). Allografts have also been considered a useful source to improve the clinical outcomes in tendon replacement (Gazdag et al., 1995). However, they have been shown to induce chronic inflammatory and immune responses compromising the scaffold biomechanics, and require a long time for the integration and remodelling. Moreover, they can be a potential source of infectious disease transmission (Pinkowski et al., 1996; Zheng et al., 2005; Eastlund 2006). In recent years, decellularisation techniques of allo- or xenografts have been highly investigated due to their biocompatibility, extracellular matrix and biomechanical features resembling native tissue (Lovati et al., 2016; Harrison and Gratzer, 2005; Cartmell and Dunn, 2000; Tischer et al., 2007; Gilbert et al., 2006) along with the absence of adverse immune response due to the removal of donor cells and antigen debris (Hudson et al., 2004; Macchiarini et al., 2008; Ueda et al., 2006).

In our previously published review on tendon decellularisation (Lovati et al., 2016), we identified in the equine species the most suitable in terms of proper dimensions, tissue retrieval and supply, as also supported 
by others (Youngstrom et al., 2013; Burk et al., 2014). In addition, we recognised tri(n-butyl) phosphate (TBP) as the most efficient agent to reach a complete cell removal while maintaining all requirements for a functional and safe tendon substitute, as also described in other animal species (Cartmell and Dunn, 2000; Deeken et al., 2011). The peracetic acid (PAA) has been commonly reported as a potent oxidizing agent used to sterilise collagen tissues (Gilbert et al., 2006; Kemp, 1994). Moreover, PAA can be also used to enhance tissue permeability for the detergent penetration and cell colonisation within the dense tendon structure (Deeken et al., 2011; Whitlock et al., 2007; Woon et al., 2011; Woon et al., 2012; Raghavan et al., 2012; Schmitt et al., 2013). Among these studies, only Woon et al. (2011) compared the efficacy of different concentrations of PAA (2, 5 and $10 \%$ ) after sodium dodecyl sulphate (SDS)-based decellularisation of human tendons. Similarly, only Deeken et al. (2011) studied the efficacy of $0.1 \%$ PAA associated to 1 or $2 \%$ TBP detergent to decellularise porcine tendons.

Our study aims to identify an effective decellularisation protocol to obtain an extracellular matrix scaffold capable of both supporting viable reseeded cells and integrating with the host tissues facilitating the regeneration of injured tendons.

In the present study, we aim to remove intrinsic tendon cells from large sized equine superficial digital flexor tendons (SDFT) by means of the $1 \%$ TBP detergent associated or not to multiple concentrations of PAA (1, 3 and $5 \%$ ), as never tested in vitro. Our hypothesis is that the treatment with low concentrations of PAA could aid in removing the cellular component of the equine SDFT without altering the intrinsic structure of the decellularised matrix, such as sulphated glycosaminoglycans (sGAG) that are highly conserved across species (Gilbert et al., 2006; Getgood and Bollen, 2010) and are fundamental for the tissue integration and regeneration. The purpose of this study is to identify a valid and standardised protocol of tendon decellularisation in order to further develop suitable xenografts as promising biological substitutes - different from allo- and autografts - in case of severe tendon lesions. After a validation by in vivo testing, the novel off-the-shelf scaffold could be used to replace tendon damages and to promote an efficient host integration and remodelling, thus offering an early return to function after implantation.

\section{Materials and Methods}

\section{Experimental design}

Ten equine SDFTs were decellularised with a novel combination of two acting agents at various concentrations. Each sample, including the native tendon, was then analysed using various techniques: histology and histomorphometry (Haematoxylin and Eosin - H\&E; Alcian blue staining), biochemical characterisation (DNA, GAG and collagen content), biomechanical characterisation, and cytotoxicity testing. Each investigation was performed on samples from each donor in duplicate. The best decellularisation protocol was chosen following the aforementioned examinations and the resulting tendon decellularised scaffold was reseeded with murine fibroblasts and tested for cell viability, histologic analysis, and DNA and collagen content.

\section{Harvesting and preparation of equine digital flexor tendons}

Fresh equine SDFT were harvested from the forelimbs of adult horses ( $n=10$; mean age $10 \pm 7$ years) at the slaughterhouse. A $10 \mathrm{~cm}$ length portion of the mid-third of the SDFT was excised, dissected for exceeding paratenon, washed in phosphate-buffered saline (PBS +/+, Sigma Aldrich, Milan, Italy), and immediately dry-stored at $-80^{\circ} \mathrm{C}$. Then, specimens were thawed at room temperature (RT) in saline solution and longitudinally sectioned into five slices by means of an electric slicer (RGV 25, RGV s.r.l., Como, Italy), then frozen again at $-80{ }^{\circ} \mathrm{C}$ until processing. The specimen dimensions were approximately $10 \mathrm{~cm}$ (length) $\times 1.5 \mathrm{~cm}($ width $) \times 0.3 \mathrm{~cm}$ (thickness) .

\section{Decellularisation protocols and methods}

Two tendon slices of each donor were chosen randomly and treated using one of the following protocols: (1) $1 \%$ TBP followed by $1 \%$ PAA; (2) $1 \%$ TBP followed by $3 \%$ PAA; (3) $1 \%$ TBP followed by $5 \%$ PAA, and (4) $1 \%$ TBP. A slice of each donor was stored at $-80{ }^{\circ} \mathrm{C}$ to represent the untreated control (native tendon, NT). Decellularisation of the scaffolds was performed using a multiple step process. Each step was carried out in $50 \mathrm{~mL}$ tubes in $40 \mathrm{~mL}$ of different solutions.

For the thawing phase, slices were immersed in PBS without sodium and magnesium (PBS-/-) at RT for $30 \mathrm{~min}$. Then, all specimens were decellularised in $1 \%$ TBP buffered in $1 \mathrm{M}$ Tris- $\mathrm{HCl} \mathrm{pH} 7.8$ for $24 \mathrm{~h}$ at RT under agitation on an orbital stirrer. Following this, slices were rinsed twice in $\mathrm{ddH}_{2} \mathrm{O}$ at $\mathrm{RT}$ for $15 \mathrm{~min}$ and stored in PBS -/- at $4{ }^{\circ} \mathrm{C}$ for $24 \mathrm{~h}$ to remove residual detergents. After this, in order to remove any residual DNA within the dense tendon matrix, the specimens were immersed in $0.0025 \%$ DNAse-I in PBS +/+ at RT under agitation for $4 \mathrm{~h}$, followed by two washes in $\mathrm{ddH}_{2} \mathrm{O}$ for $15 \mathrm{~min}$ and two washes in PBS -/- for $15 \mathrm{~min}$. The final step involved an incubation in $1 \%, 3 \%$ or $5 \%$ aqueous solution of PAA (stock solution $32 \%$ ) for groups 1,2 and 3 under agitation at RT for $4 \mathrm{~h}$. Specimens of group 4 did not undergo to any PAA treatment, but they were incubated in PBS -/- under agitation at RT for $4 \mathrm{~h}$ as a positive control to evaluate the PAA efficacy. Finally, slices were rinsed twice in $\mathrm{ddH}_{2} \mathrm{O}$ for $15 \mathrm{~min}$, twice in PBS -/-, and then either stored in PBS -/- at $4{ }^{\circ} \mathrm{C}$ for $24 \mathrm{~h}$ for the biomechanical analysis or dry-stored at $-80{ }^{\circ} \mathrm{C}$ for other analyses. All reagents were Sigma-Aldrich (Milan, Italy).

\section{Histologic evaluation}

Samples for histology were fixed in $10 \%$ buffered formaldehyde for $24 \mathrm{~h}$ at RT, dehydrated, paraffin embedded and longitudinally sectioned at $5 \mu \mathrm{m}$. Sections were stained with H\&E to assess the cellular components (intact cells, cell debris or vacuolated nuclei) and collagen fibre morphology, and Alcian blue staining to evaluate the sulphated proteoglycan content, according to standard protocols. Photomicrographs were captured using an 
Olympus IX71 light microscope and an Olympus XC10 camera (Tokyo, Japan). To semi-quantitatively assess the cell density, photomicrographs were evaluated by two blinded observers by quantifying the number of stained nuclei using Image $\mathrm{J} 1.45 \mathrm{~s}^{\circledR}$ software (open source: http:// rsbweb.nih.gov/ij) and data were reported as mean cell density $\left(\right.$ cells $\left./ \mathrm{mm}^{2}\right)$ per treatment and as percentage of cell removal.

\section{Biochemical characterisation: DNA, sGAG and collagen content \\ Sample digestion for DNA and SGAG quantification}

Segments of decellularised, native tendon, and eventually reseeded matrix were weighed in order to normalise the biochemical data on sample dry weight. Then, specimens were minced and digested in $2 \mathrm{mg} / \mathrm{mL}$ proteinase $\mathrm{K}$ (pH 7.6) (Sigma-Aldrich, Milan, Italy) at $56^{\circ} \mathrm{C}$ for $16 \mathrm{~h}$ under agitation. Digested samples were centrifuged at $10,000 \times g$ for $10 \mathrm{~min}$ at RT and the supernatant was collected for analyses.

DNA assay was performed to quantify the potential cellular remains after the decellularisation processes. DNA content was measured in the supernatant using a cell proliferation assay $\left(\mathrm{CyQuant}{ }^{\circledR} \mathrm{kit}\right.$ - Life Technologies, Monza, Italy) following the manufacturer's instructions. Fluorescence was measured by means of a spectrophotometer (Perkin Elmer Victor X3 microplate reader) at an excitation/ emission wavelength of $480 / 520 \mathrm{~nm}$. The quantification of sGAG was performed on decellularised and native tendons using the 1,9-dimethylmethylene blue (DMMB) dye-binding assay (Sigma-Aldrich, Milan, Italy) and compared to a standard curve of chondroitin sulphate (Blyscan - Biocolor, Magenta, Italy). Briefly, the samples were incubated in $40 \mathrm{mM}$ glycine/ $\mathrm{NaCl}(\mathrm{pH} 3.0)$ with $16 \mathrm{mg} / \mathrm{mL}$ DMMB at RT. The sGAG concentration was determined by reading the absorbance at $500 \mathrm{~nm}$ (Perkin Elmer Victor X3 microplate reader).

Data from DNA and sGAG content analysis were normalised to the sample dry weights.

\section{Sample digestion for collagen quantification}

In order to remove the proteoglycans, about $10 \mathrm{mg}$ of each sample - decellularised and native tendons, and reseeded matrices - were stirred in a solution of $4 \mathrm{M}$ guanidine$\mathrm{HCl}$ in $0.05 \mathrm{M}$ sodium acetate $(\mathrm{pH} 5.8)$ at $4{ }^{\circ} \mathrm{C}$, and then centrifuged at $30000 \times g$ for $30 \mathrm{~min}$ at $4{ }^{\circ} \mathrm{C}$. The supernatant was removed and samples washed three times using $0.5 \mathrm{M}$ acetic acid. The collagen residue was added to a solution of $1 \mathrm{mg} / \mathrm{mL}$ pepsin in $0.5 \mathrm{M}$ acetic acid at $4{ }^{\circ} \mathrm{C}$ for $3 \mathrm{~d}$, then samples were centrifuged at $30000 \times g$ for $30 \mathrm{~min}$ at $4{ }^{\circ} \mathrm{C}$ and the supernatant was collected as described elsewhere (Taskiran et al., 1999). Following, $100 \mu \mathrm{L}$ of samples were mixed with $900 \mu \mathrm{L}$ of Sirius Red in acetic acid ( $0.5 \mathrm{M}$, all reagents from Sigma-Aldrich, Milan, Italy) and incubated at RT for $20 \mathrm{~min}$. After the incubation period, the samples were centrifuged at $16,000 \times g$ for $30 \mathrm{~min}$, the supernatant was disposed, and the collagen bound dye complex was dissolved in $0.5 \mathrm{M}$ sodium hydroxide (Alkali reagent-Biocolor, Magenta, Italy). The absorbance of the supernatant was read in a spectrophotometer at $540 \mathrm{~nm}$ against sodium hydroxide $(0.5 \mathrm{M})$ as blank. The obtained optical densities were interpolated in a curve of absorbance, using collagen type I from rat-tail soluble in acetic acid (BD Bioscience, Milan, Italy) as standard.

Data obtained were normalised to the sample dry weight and expressed as total acid-soluble collagen ( $\mu \mathrm{g} /$ $\mathrm{mg})$.

\section{Biomechanics}

To perform the biomechanical tests, rectangular specimens were obtained from the decellularised and native tendons. To avoid the sample slip at the machine grips, the final portions of the rectangular specimens were interposed and fixed by cyanoacrylate glue between two sheets of sandpaper.

Mechanical testing was performed at RT using an electromagnetic testing machine (MTS Synergie, MTS Systems Corporation, Eden Prairie, MN, USA), equipped with a load cell of $1 \mathrm{kN}$. The mean dimensions of the samples from equine decellularised or native tendons, measured between the grips, were $39 \pm 8 \mathrm{~mm}$, $14 \pm 2 \mathrm{~mm}$ width and $2.4 \pm 0.6 \mathrm{~mm}$ thickness. Tension protocol consisted of multi-ramp stress relaxation tests, followed by the strain-controlled tension up to failure. For stepwise stress relaxation tests, three tension steps up to $2 \%$ strain were applied, at $1 \% / \mathrm{s}$ strain rate, followed by $1,000 \mathrm{~s}$ stress relaxation. The machine crosshead was returned to the initial position before running the failure test, also conducted at $1 \% / \mathrm{s}$ strain rate. The pure elastic response was calculated from the equilibrium data of the stress relaxation tests, and indicated as $\mathrm{E}_{\mathrm{r}}$. The tendon hyperelastic response and the failure stress and failure strain were derived from the failure test, along with the elastic response at high strains, elastic modulus (EM), evaluated as the slope of the final linear portion of the stress-strain curve. Five preconditioning cycles were applied to every sample before the tests.

\section{In vitro cytotoxicity of the decellularisation detergents and cytocompatibility of the decellularised tendon matrix}

These analyses were carried out to assess the potential cytotoxicity of the decellularisation detergents of the tested experimental solutions on NIH-3T3 murine fibroblasts.

Firstly, NIH-3T3 cells were seeded $3 \times 10^{3} / \mathrm{cm}^{2}$ in 96-well plates in complete medium (CM) consisting of Dulbecco's modified Eagle's medium high glucose (Gibco, Life Technologies, Monza, Italy), $10 \%$ foetal bovine serum (FBS, Hyclone, Life Technologies, Monza, Italy), $100 \mathrm{U} / \mathrm{mL}$ penicillin-streptomycin, $2 \mathrm{mM}$ L-glutamine, $1 \%$ sodium pyruvate and $1 \%$ HEPES (all from Gibco, Life Technologies, Monza, Italy). Samples derived from decellularised tendons (treatments) and native tendons (NT) were cut into $5 \times 5 \mathrm{~mm}$ pieces and placed into $70 \%$ ethanol for $10 \mathrm{~min}$ under agitation. Then, they were washed three times in PBS and incubated in $5 \mathrm{~mL}$ of CM for $96 \mathrm{~h}$ at $37^{\circ} \mathrm{C}$ under agitation, hereon called conditioned media and used to establish an indirect toxicity test. Indeed, the NIH- 
$3 \mathrm{~T} 3$ cells were cultured in $200 \mu \mathrm{L}$ of the aforementioned conditioned media, fresh CM (negative control, NC) or $0.5 \%$ Triton-X100 medium (positive control, PC) for $72 \mathrm{~h}$.

Thus, the cell viability was analysed by a colorimetric assay in which the 3(4,5-dimethylthiazole-2-yl)-2,5diphenyltetrazolium-bromide (MTT, Sigma-Aldrich, Milan, Italy) to formazan blue by viable cells. Briefly, $500 \mu \mathrm{L}$ of MTT in DMEM without phenol red $(0.5 \mathrm{mg}$ $\mathrm{MTT} / \mathrm{mL}$, dilution 1:10) was added to each well containing the cell monolayer and incubated at $37^{\circ} \mathrm{C}$ for $4 \mathrm{~h}$. Following this, medium was removed and the formazan crystals were solubilised with $500 \mu \mathrm{L}$ of pure isopropanol for $30 \mathrm{~min}$ at RT under agitation. The absorbance was determined at $570 \mathrm{~nm}$ by means of a microplate reader (Perkin Elmer Victor X3). Three replicates were considered per sample. Data were reported as absorbance values. Moreover, the mitochondrial function was then calculated for the cytotoxicity assay, as a percentage of the NC considered as $100 \%$.

\section{Repopulation of the decellularised matrix}

Tendons decellularised by means of TBP $+3 \%$ PAA were cut into pieces measuring $5 \mathrm{~mm}$ (length) $\times 5 \mathrm{~mm}$ (width) $\times 3 \mathrm{~mm}$ (thickness). Then, they were sterilised into $70 \%$ ethanol for $10 \mathrm{~min}$ under agitation and washed three times in PBS, finally, left unseeded as negative control (decellularised matrix, DM) or seeded with NIH-3T3 murine fibroblasts at a concentration of $2.6 \times 10^{4} / \mathrm{mm}^{3}$ (reseeded matrix, RM) and cultured in CM. To seed the grafts, $150 \mu \mathrm{L}$ of the cell suspension was placed onto the surface of the tendon. After $2 \mathrm{~h}$ of incubation at $37^{\circ} \mathrm{C}$ in a $5 \% \mathrm{CO}_{2}$ in humidified incubator, the medium was added and both the unseeded and seeded tendon matrices were statically cultured for $7 \mathrm{~d}$. The CM was changed every $3 \mathrm{~d}$. Samples were then evaluated for the seeding efficiency by measuring the DNA content of the initial cell amount and of the retrieved cells onto the reseeded matrix after $24 \mathrm{~h}$. Furthermore, after $7 \mathrm{~d}$, the samples were analysed for histology (H\&E), Live \& Dead assay, and collagen content.

\section{Live \& Dead assay}

To evaluate the cell viability of NIH-3T3 fibroblasts seeded onto the decellularised matrix, a Live \& Dead Viability/ Cytotoxicity test (Life Technologies, Monza, Italy) was performed according to the manufacturer's instructions. Briefly, after $7 \mathrm{~d}$ of culture, the DM and RM constructs were labelled with Live \& Dead stain consisting in $2.5 \mu \mathrm{L}$ calcein AM and $10 \mu \mathrm{L}$ ethidium homodimer-1 dissolved in $5 \mathrm{~mL}$ of PBS. Then, the samples were incubated at RT for $30 \mathrm{~min}$ before analysing microscopically. Live cells appeared green, while dead cells fluoresced red.

\section{Statistical analysis}

Data were recorded from ten SDFT derived from ten different horses $(n=10)$. Each investigation was performed on samples from each donor in duplicate. The cytotoxicity test was performed in triplicate.

The normal distribution of data was ascertained with the Shapiro-Wilk test. Comparisons among groups were analysed with one-way analysis of variance (ANOVA) (Graph Pad Prism v5.00 Software Inc., San Diego,
CA, USA) coupled with Bonferroni's post hoc test. For reseeding studies, a paired $t$-test was performed. All data are expressed as means \pm standard error (SE), unless specified otherwise. Values of $p<0.05$ were considered statistically significant.

\section{Results}

\section{Histologic analysis}

The H\&E photomicrograph of native tendons showed normal elongated and intact cell nuclei of tendon fibroblasts laying between regular collagen fibres in lacunae (Fig. 1a). The sulphated proteoglycans, located within the endotenon and near the blood vessels, were stained deep blue with the Alcian Blue. The well-organised collagen fibres appeared like pink coloured compact bundles (Fig. 1b). Native tendons depicted a common collagen pattern with a cell density of $206 \pm 142$ cells $/ \mathrm{mm}^{2}$ with a very significant difference $(p<0.001)$ compared to all the decellularised tendons (Fig. 1c).

Tendons treated with both TBP $+1 \%$ PAA and TBP $+3 \%$ PAA had a decreased cell density compared to the NT with a $69 \%$ and $98 \%$ of cells removed, respectively, and histologic analysis showed a well-preserved pattern of the collagen fibres demonstrating the maintenance of the tissue architecture. In TBP + $1 \%$ PAA, the H\&E staining depicted a mild presence of intact cells with well-formed nuclei, together with a large number of vacuolated cell nuclei or diffuse cellular debris (Fig. 2a). TBP $+3 \%$ PAA showed very few vacuolated cells associated with scarce cell debris (Fig. 2c). For the Alcian blue staining, the tendons treated with TBP $+1 \%$ PAA showed wellpreserved proteoglycan content (Fig. 2b). Conversely, $\mathrm{TBP}+3 \%$ PAA treated samples depicted a mild decrease of proteoglycans, despite no alteration of collagen fibres was detected in both TBP $+1 \%$ PAA and TBP $+3 \%$ PAA (Fig. 2d).

Specimens treated with TBP $+5 \%$ PAA had $99 \%$ cell removal with respect to the NT. In this group, no nuclear material (vacuolated nuclei or cell debris) was evident at the H\&E staining. Here, a sparsely distributed opening of the collagen fibres was identified together with an increased pattern of the tendon crimp (Fig. 3a). The Alcian Blue staining in TBP $+5 \%$ PAA treated tendons demonstrated a significant decrease of proteoglycans that appear as light blue bundles within the augmented inter-fascicular spaces. Similarly, also the collagen fibres appeared as light pink coloured bundles among the disrupted tendon crimp pattern (Fig. 3b).

Despite a significantly lower cell density in the TBP treated samples compared to NT with $63 \%$ cell removal, the remaining cells seemed to be intact with no signs of vacuolisation of the nuclei or cell disruption. Similarly to TBP $+1 \%$ PAA and TBP $+3 \%$ PAA, TBP treatment preserved a good pattern of the collagen fibres (Fig. 3c). Overall, TBP treated samples showed a well-preserved proteoglycan content similar to those treated with $\mathrm{TBP}+1 \%$ PAA, as well as well-organised collagen fibres appearing like pink coloured compact bundles (Fig. 3d). 
H\&E

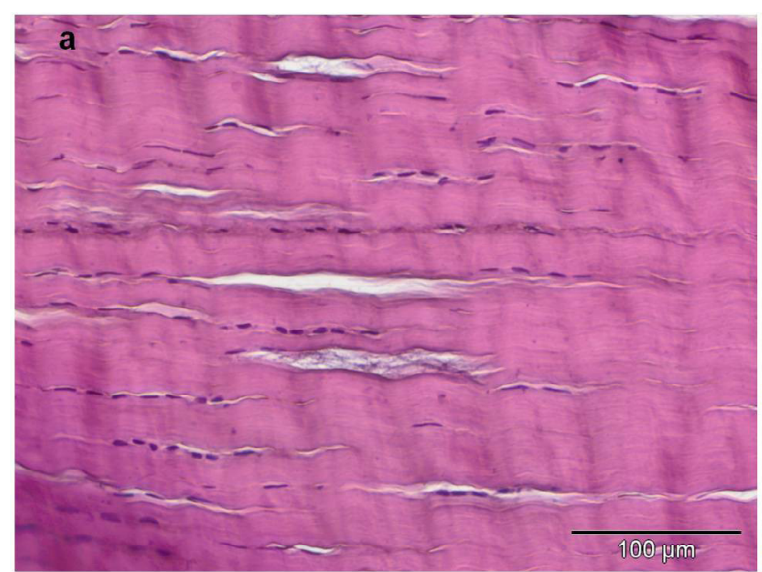

ALCIAN BLUE

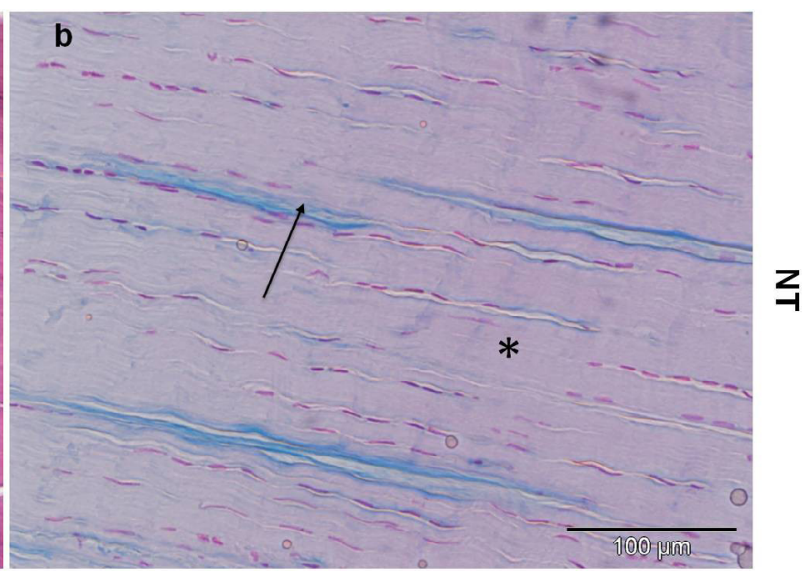

C

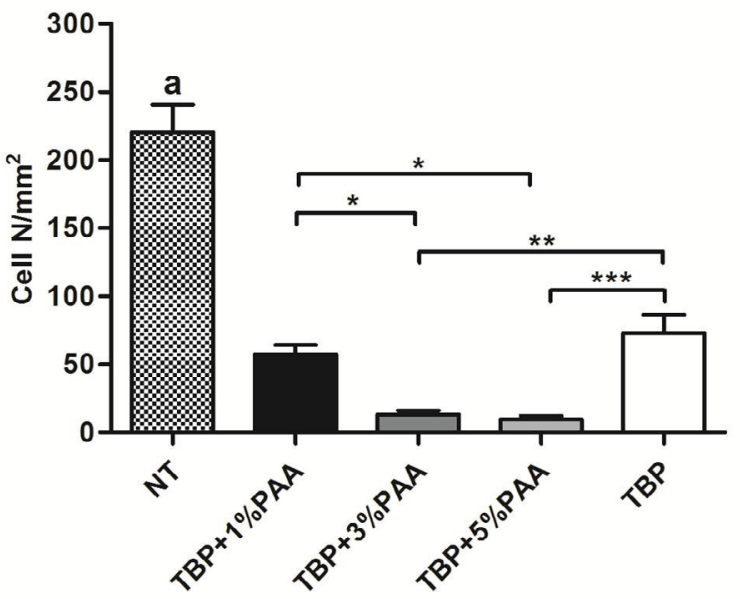

Fig. 1. Representative histologic panel of native tendons (NT) (scale bars $100 \mu \mathrm{m}$ ). Native tendons stained with haematoxylin and eosin (H\&E) (a) and with Alcian blue (b). Black arrow = proteoglycans; asterisk = collagen fibres in compact bundles. The histogram reports the histomorphometric cell count (cells $/ \mathrm{mm}^{2}$ ) of the native and treated tendons. Comparisons among groups were analysed with one-way analysis of variance (ANOVA) coupled with Bonferroni's post hoc test. * $p<0.05 ; * * p<0.01$; a, *** $p<0.001$.

\section{Biochemical analyses on decellularised and native tendons}

The ability of the decellularisation protocols to remove the cell component was quantified by DNA content analysis. The DNA content in all treated samples was reduced significantly compared to the NT ( $p<0.001)$, supporting the histologic cell count. More importantly, a decreased DNA content was found in samples treated with TBP $+3 \%$ PAA and TBP $+5 \%$ PAA compared to those treated with TBP $+1 \%$ PAA and TBP $(p<0.01$ and $p<0.001$, respectively). The DNA content in samples treated with $\mathrm{TBP}+3 \%$ PAA and TBP $+5 \%$ PAA responds to the minimal criteria (50 ng/mg dry weight) set by Crapo et al. (2011) to satisfy the intent of tissue decellularisation (Fig. 4a, dotted line). Fig. 4b, reporting the quantification of the sGAG content, depicted a significant decrease of sGAG content in tendon treated with TBP $+5 \%$ PAA when compared to NT $(p<0.001)$, and also compared to TBP $+1 \%$ PAA and TBP $(p<0.001$ and $p<0.01$, respectively). No significant differences were detected in the samples decellularised with TBP $+1 \%$ PAA, $\mathrm{TBP}+3 \% \mathrm{PAA}$ and TBP with respect to NT.

\section{Total collagen content in decellularised and native tendons}

A significant decrease in collagen content was found in tendons treated with all decellularisation protocols with respect to NT $(p<0.001)$ (Fig. 4c). In contrast, the TBP group showed a higher collagen content compared to TBP $+1 \%$ PAA $(p<0.05)$, TBP $+3 \%$ PAA and TBP $+5 \%$ PAA $(p<0.01)$.

\section{Biomechanical tests for decellularised and native tendons}

The results of stress-relaxation tests conducted on native and decellularised samples with $\mathrm{TBP}+1 \%$ PAA, $\mathrm{TBP}+3 \%$ PAA, TBP $+5 \%$ PAA and TBP are reported in Fig. 4. The Fig. 5a reports a representative example of a multi-step relaxation test and the results of the relaxation moduli $\left(\mathrm{E}_{\mathrm{r}}\right)$ for the three ramps are depicted in the histogram in Fig. 5b. The results of the failure tests report a hyperelastic response, as shown in Fig. 5c for a representative specimen. The Fig. $5 \mathbf{d}$ shows the elastic modulus (EM) at high strains. The tendons treated with all the decellularisation protocols did not show significant 
H\&E
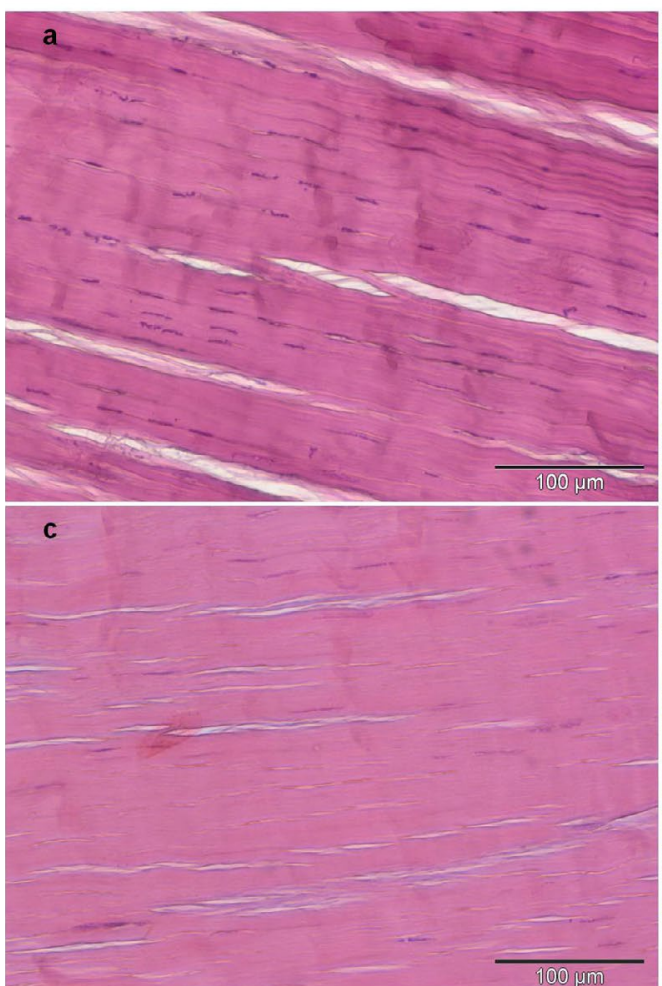

\section{ALCIAN BLUE}

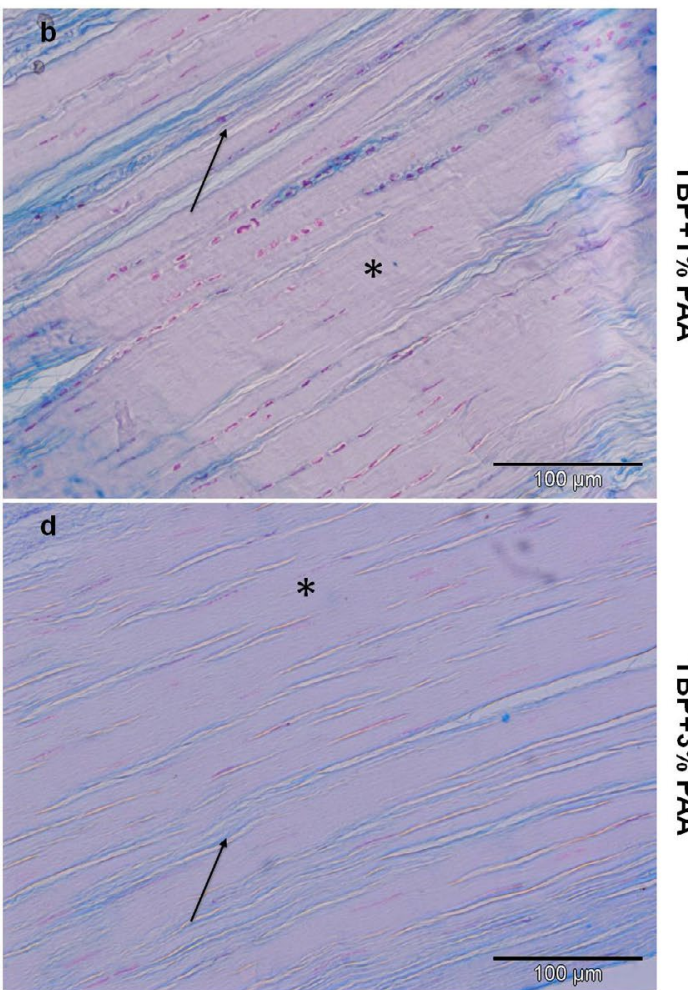

Fig. 2. Representative histologic panel of tendons decellularised with TBP $+1 \%$ PAA and TBP $+3 \%$ PAA (scale bars $100 \mu \mathrm{m})$. The left panels depict haematoxylin and eosin (H\&E) staining; the right panels depict Alcian blue staining. Tendon decellularised with TBP $+1 \%$ PAA $(\mathbf{a}, \mathbf{b})$; tendon decellularised with TBP $+3 \%$ PAA $(\mathbf{c}, \mathbf{d})$. Black arrow $=$ proteoglycans; asterisk $=$ collagen fibres in compact bundles.

H\&E
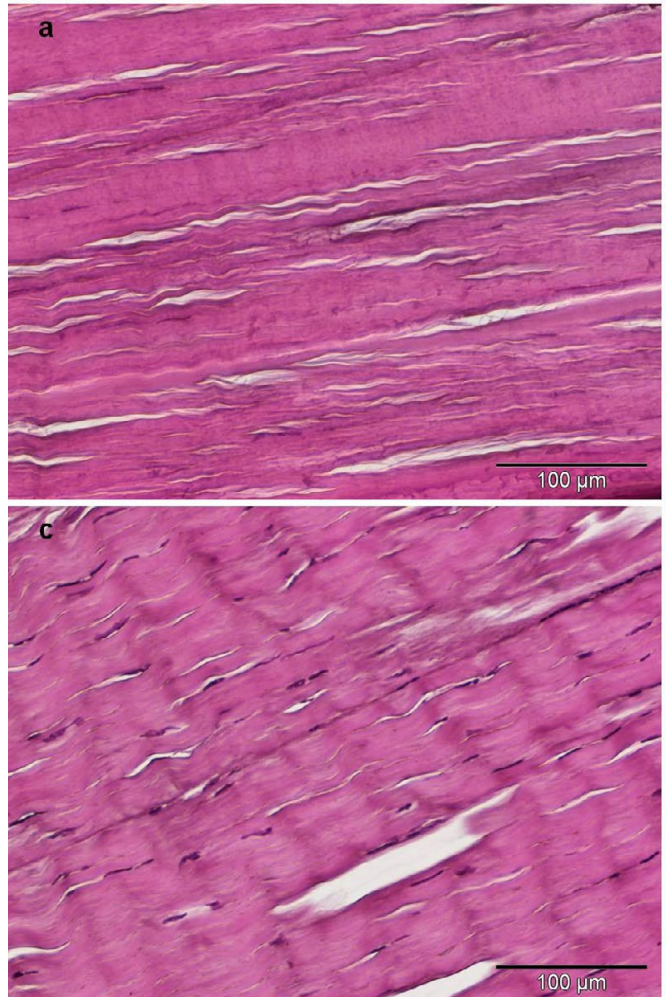

ALCIAN BLUE

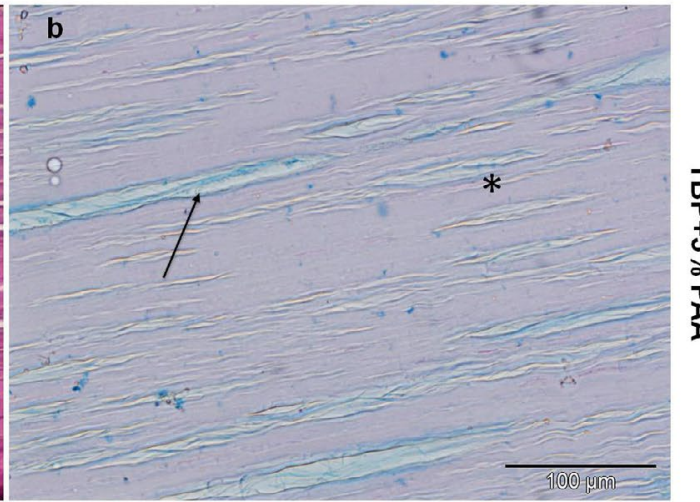

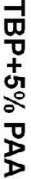

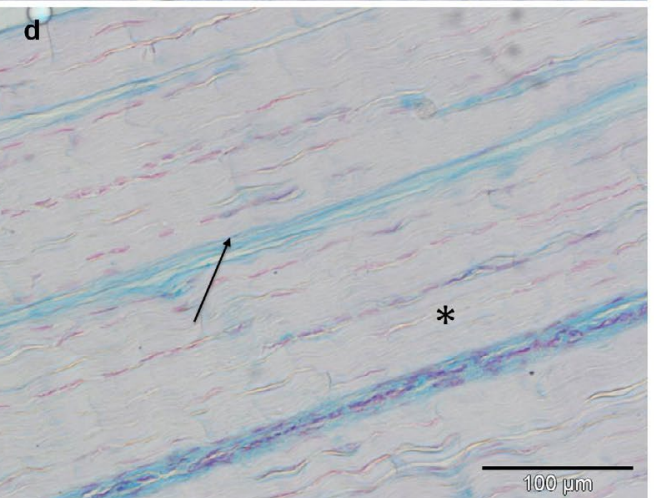

Fig. 3. Representative histologic panel of tendons decellularised with TBP $+5 \%$ PAA and TBP alone (scale bars: $100 \mu \mathrm{m}$ ). The left panels depict haematoxylin and eosin (H\&E) staining; the right panels depict Alcian blue staining. Tendon decellularised with TBP $+5 \%$ PAA $(\mathbf{a}, \mathbf{b})$; tendon decellularised with TBP alone $(\mathbf{c}, \mathbf{d})$. Black arrow $=$ proteoglycans; asterisk $=$ collagen fibres in compact bundles. 
a

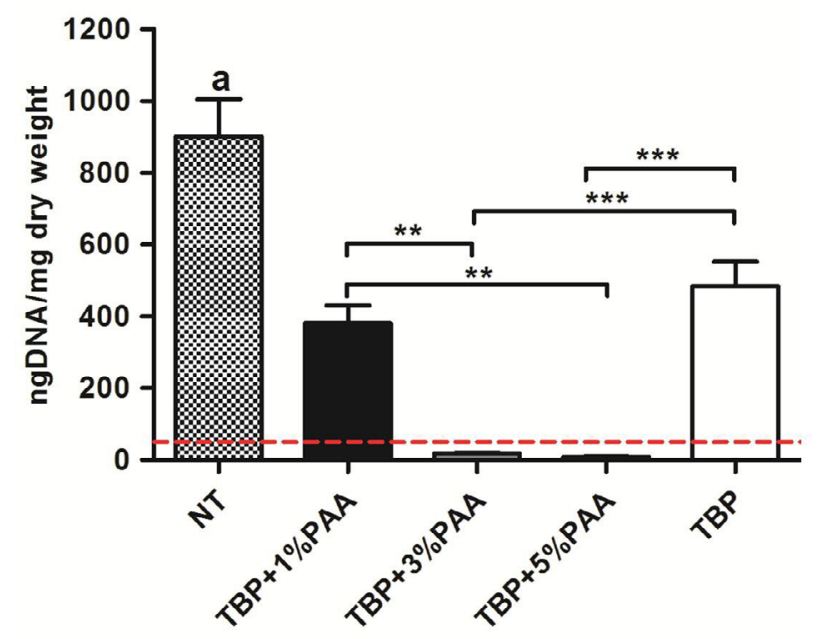

b

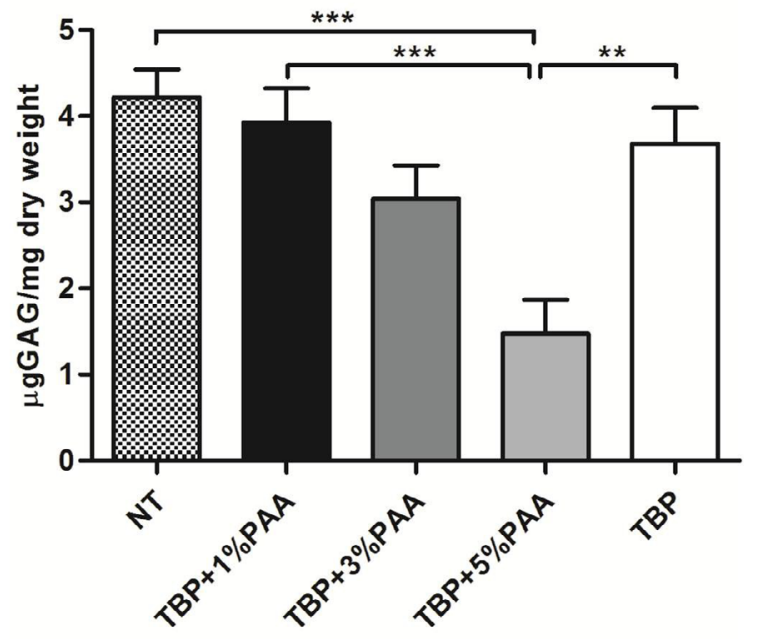

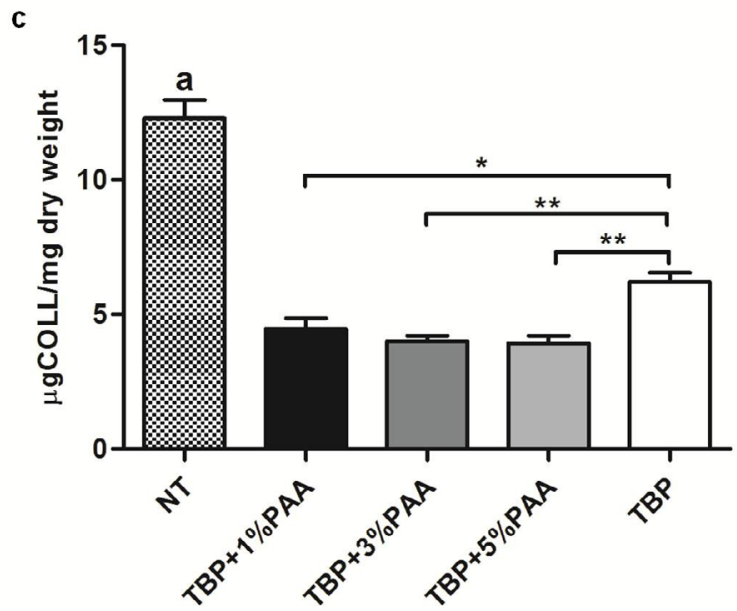

Fig. 4. DNA, sulphate glycosaminoglycans (sGAG) and collagen content. Effects of the decellularisation protocols on DNA (ng/mg dry weight) (a); the dotted line represents the limit of DNA content at $50 \mathrm{ng} / \mathrm{mg}$ dry weight identified by Crapo et al. (2011). Effects of the decellularisation protocols on sGAG content ( $\mu \mathrm{g} / \mathrm{mg}$ dry weight) (b). Effects of the decellularisation protocols on collagen content $(\mu \mathrm{g} / \mathrm{mg}$ dry weight $)(\mathbf{c})$. Comparisons among groups were analysed with one-way analysis of variance (ANOVA) coupled with Bonferroni's post hoc test. * $p<0.05$; ** $p<0.01$; a, $* * * p<0.001$.

changes in EM compared to the NT, only a significant difference was found between TBP $+1 \%$ PAA and TBP $+5 \%$ PAA $(p<0.05)$ as reported in Fig. $5 \mathbf{d}$. This finding indicated a stiffer behaviour of tendons treated with $\mathrm{TBP}+1 \%$ PAA. The EM value for NT was $181 \pm 78 \mathrm{MPa}$.

Failure stains and stress are shown in Fig. 5. There was not a significant difference either in the percentage of the failure strain measured after the decellularisation with respect to the NT (Fig. 5e) or in the failure stress among groups (Fig. 5f).

\section{Cytotoxicity tests of the decellularised tendons}

NIH-3T3 murine fibroblasts were used to evaluate the cytotoxicity of decellularised tendon matrices using an MTT assay (Fig. 6). Absorbance values of cells cultured in conditioned media as well as $\mathrm{NC}$ were significantly higher than PC for $p<0.001$, indicating a normal cell proliferation. Cells cultured in TBP conditioned medium showed a lower absorbance compared to the NC $(p<0.001)$. Similarly, cells cultured in the TBP $+5 \%$ PAA conditioned medium had a significantly lower absorbance rate compared to the NC $(p<0.001)$, but also with respect to cells cultured in TBP $+1 \%$ PAA and TBP $+3 \%$ PAA conditioned media $(p<0.01)$, and the NT conditioned medium $(p<0.05)$, indicating a decrease in cell proliferation. The mitochondrial function was defined as the relative cell number on the NC which showed a $89,91,74$ and $81 \%$ of cell viability when cells were cultured in $\mathrm{TBP}+1 \% \mathrm{PAA}$, $\mathrm{TBP}+3 \% \mathrm{PAA}, \mathrm{TBP}+5 \% \mathrm{PAA}$ and TBP conditioned media, respectively.

\section{Cell colonisation of the decellularised matrix}

Equine tendons treated with TBP $+3 \%$ PAA, which was identified as the optimal protocol, were reseeded with NIH3T3 fibroblasts for $7 \mathrm{~d}$. After culture, the Live \& Dead assay demonstrated a preserved viability of the seeded cells (Fig. $7 \mathbf{a}, \mathbf{b})$, specifically, $80 \pm 9 \%$ of living cells and $20 \pm 9 \%$ of dead cells. Moreover, cells were well distributed on 


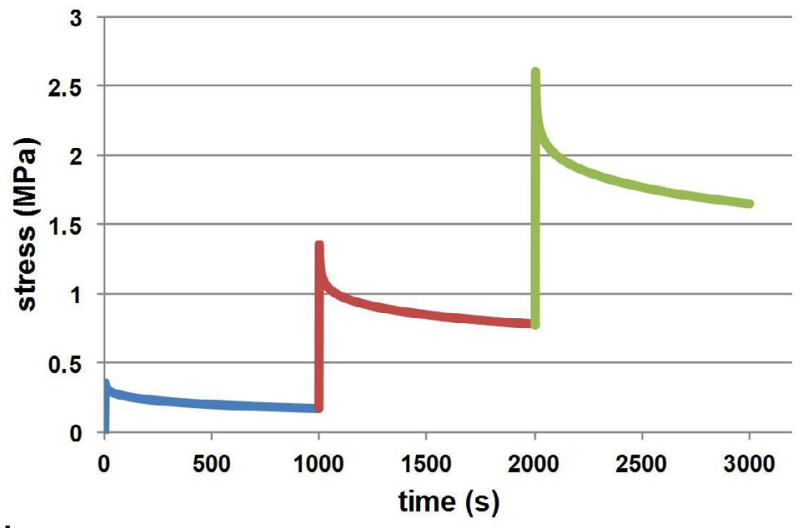

b

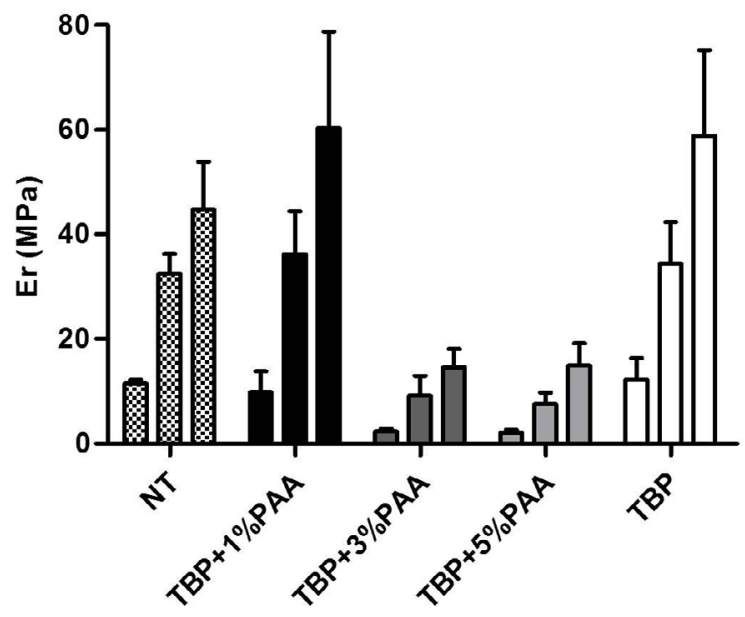

e

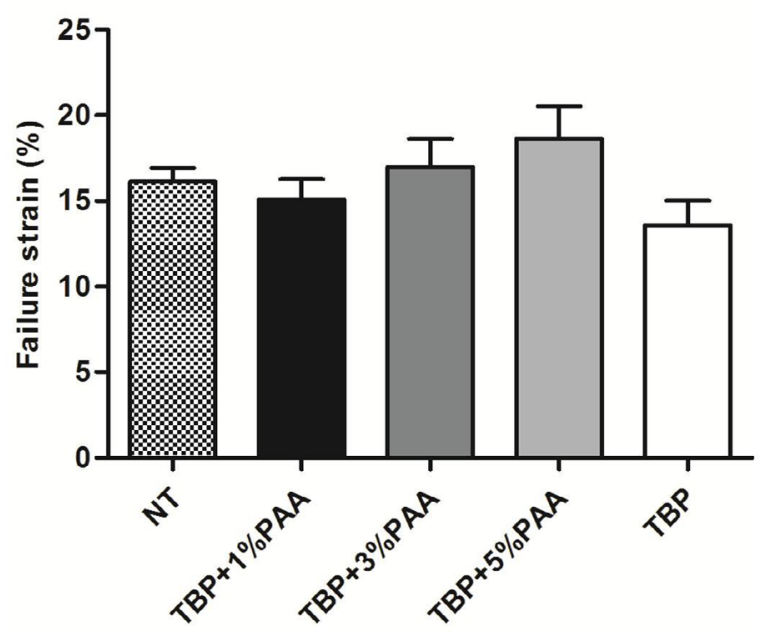

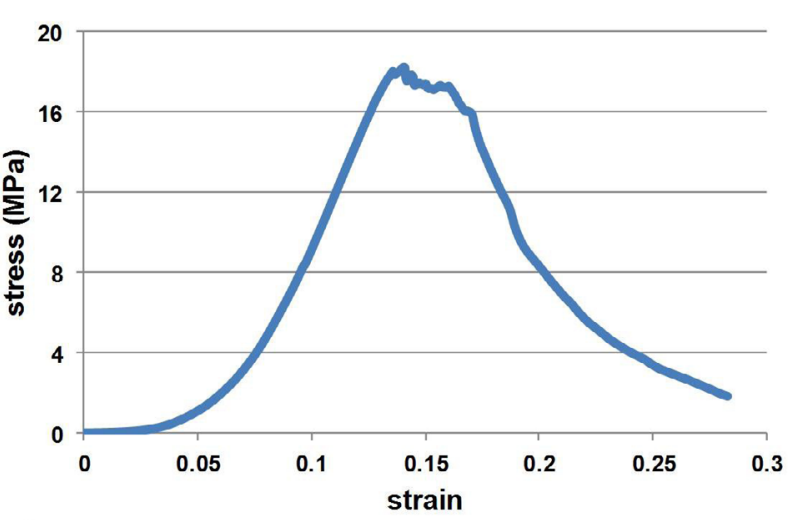

d

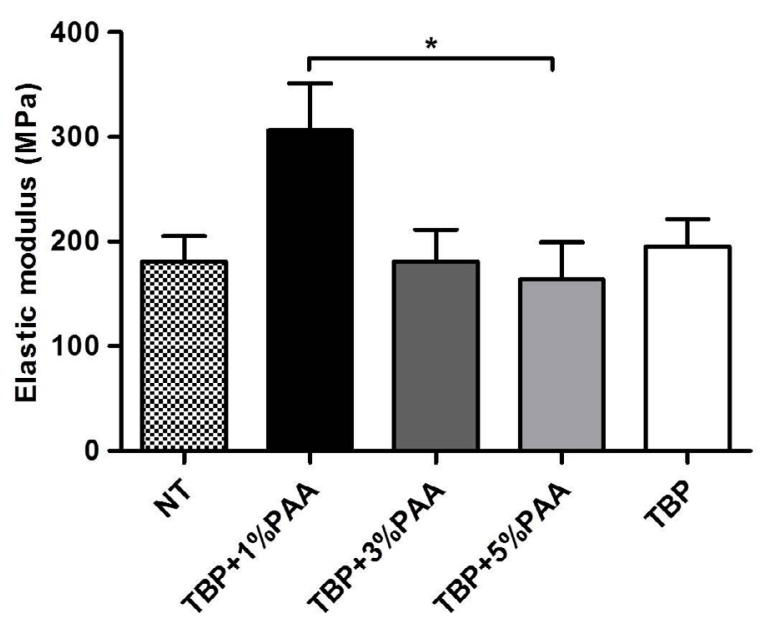

f

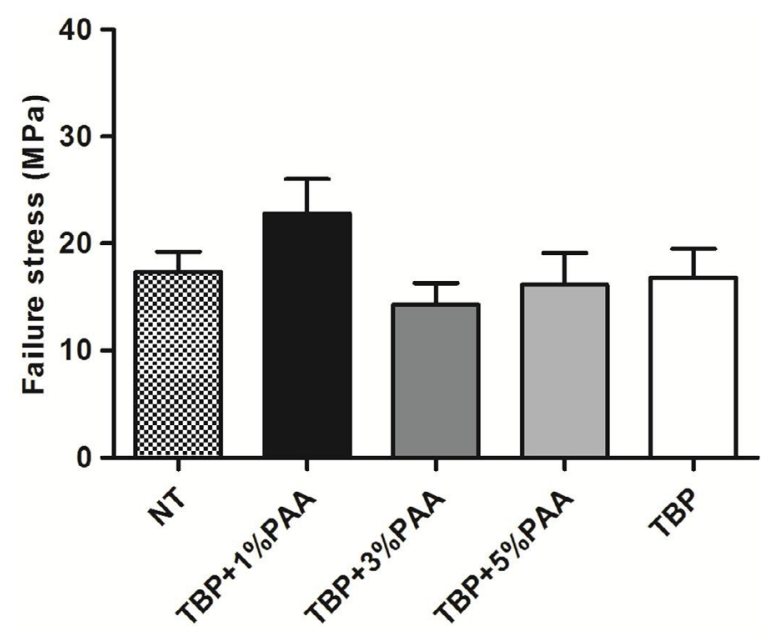

Fig. 5. Biomechanical analysis: relaxation moduli, elastic modulus, failure strain and failure stress. Representative example of a multi-step relaxation test (a). Histogram of the relaxation moduli $\left(\mathrm{E}_{\mathrm{r}}\right)$ for the three ramps comparing the native tendon (NT) and the decellularisation protocols (b). Representative graph of a failure test (c). Elastic modulus (MPa) comparison between NT and the decellularisation protocols (d). Failure strains (\%) comparing the NT and the decellularisation protocols (e). Failure stress ( $\mathrm{MPa}$ ) comparing the NT and the decellularisation protocols (f). Comparisons among groups were analysed with one-way analysis of variance (ANOVA) coupled with Bonferroni's post hoc test. $* p<0.05$. 
Fig. 6. MTT assay results for potential cytotoxicity of the decellularisation protocols. Comparisons among groups were analysed with one-way analysis of variance (ANOVA) coupled with Bonferroni's post hoc test. * $p<0.05$; $* * p<0.01 ; \mathrm{a}, * * * p<0.001$.

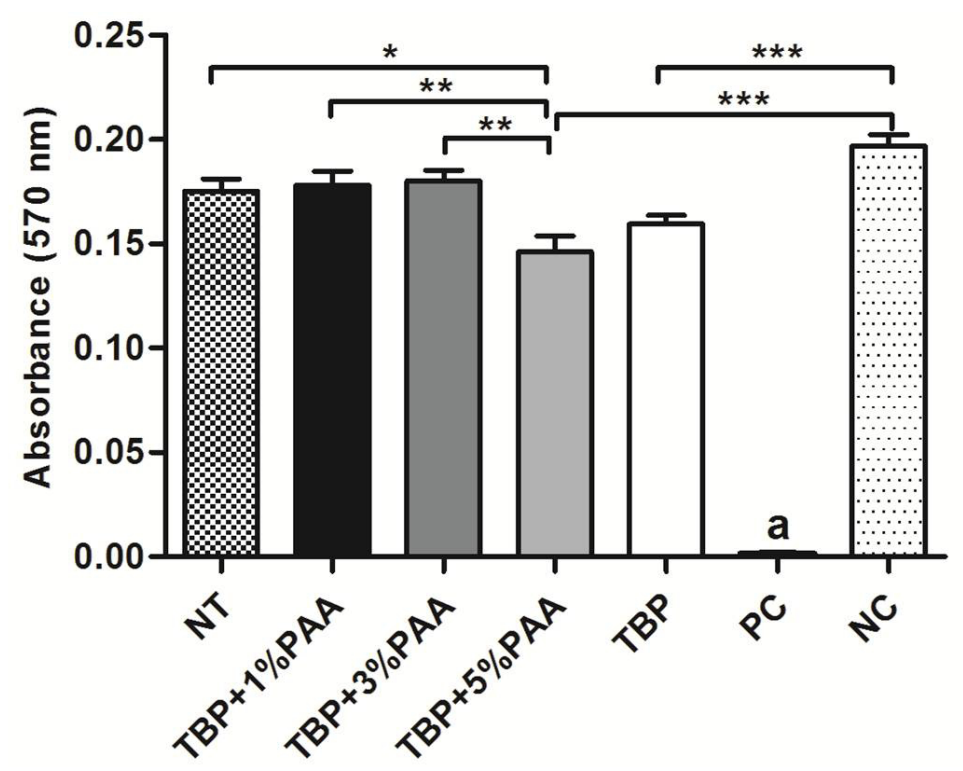

the surface of the construct forming a compact cell layer onto the RM. Similarly, the H\&E histologic staining depicted a dense and fibrous sheet of NIH-3T3 fibroblasts on the surface of the RM (Fig. 7c,d). These data strictly correlated with the higher DNA content measured in the RM constructs compared to the DM $(p<0.001)$ (Fig. 7e). Moreover, the collagen content in RM increased 1.85-fold with respect to the DM for values of $7.41 \pm 1.17 \mu \mathrm{g}$ COLL/ mg dry weight, demonstrating both cell viability and an enhanced metabolic activity.

\section{Discussion}

The use of xenogeneic decellularised tendon matrix has become an attractive approach to replace damaged tendons while preserving biomechanical properties, biocompatibility and tendon architecture (Lovati et al., 2016). Several decellularisation protocols have been investigated to generate acellular tendon scaffolds (Cartmell and Dunn, 2000; Cartmell and Dunn, 2004; Youngstrom et al., 2013; Youngstrom et al., 2015; Burk et al., 2014; Whitlock et al., 2007; Woon et al., 2011; Pridgen et al., 2011; Xing et al., 2014), with the aim to preserve as much as possible a tendon ECM suitable for cell colonisation.

Despite the interesting properties of equine flexor tendons in terms of material retrieval, mechanical strength and limited zoonotic diseases (Lovati et al., 2016), only a few studies performed the tendon decellularisation in this species (Youngstrom et al., 2013; Youngstrom et al., 2015; Burk et al., 2014; Durgam et al., 2012), although an optimum gold standard method has not been reported in the literature yet.

The aim of our study is to decellularise tendons to be used as suitable substitute for injured tendons, by resembling the native mechanical properties and improving the integration with the host tissues. Thus, with the aim to identify a standard decellularisation protocol for large equine tendons, the present study investigates the combination of two primary reagents - TBP and PAA. Their ability to efficiently remove resident cells and to increase the matrix porosity for following cell colonisation, while preserving the main features of functional tendons, is tested. Particularly, we employed a zwitterionic detergent, the TBP, known to be also a virucidal and bacteriostatic agent, frequently used in scaffold preparation for implantable grafts (Crapo et al., 2011; Deeken et al., 2011). Furthermore, to decellularise dense tissues such as tendon, TBP has been shown to be more effective than other detergents like Triton-X100 and SDS, with a good retention of the ECM constituents and mechanical properties resembling the native tissue (Cartmell and Dunn, 2000; Deeken et al., 2011).

Here, we analysed the efficacy of $1 \%$ TBP associated or not with different concentration of PAA $(1,3$, and $5 \%)$ to decellularise the equine SDFT. To do this, we worked on long length grafts from equine native tendon $3 \mathrm{~mm}$ thick slices, as the most suitable measure to obtain reliable mechanical properties of normal tendon bundles (Qin et al., 2012; Ning et al., 2012).

Our results indicated that TBP and TBP $+1 \%$ PAA protocols did not allow the efficient removal of DNA, despite the histologic findings suggesting that these treatments could maintain a good pattern of collagen fibres, as also demonstrated by others (Cartmell and Dunn, 2000; Cartmell and Dunn, 2004). Other groups, who used $1 \%$ TBP to decellularise tendons both from equine and human species (Youngstrom et al., 2013; Pridgen et al., 2011), described similar DNA values. More importantly, TBP $+3 \%$ PAA and TBP $+5 \%$ PAA treatments significantly reduced the resident cell quantity by obtaining DNA values lower than $50 \mathrm{ng} / \mathrm{mg}$ dry weight, representing the minimal criteria for potential clinical use set by Crapo et al. (2011). This low DNA content was supported also by our histomorphometric data, potentially avoiding any adverse immune response after transplantation (Crapo et al., 2011). The percentage of cell removal obtained by TBP $+3 \%$ PAA $(98 \%)$ and TBP $+5 \%$ PAA $(99 \%)$ treatments are the most effective data published to date in the field 


\section{RESEEDED MATRIX}

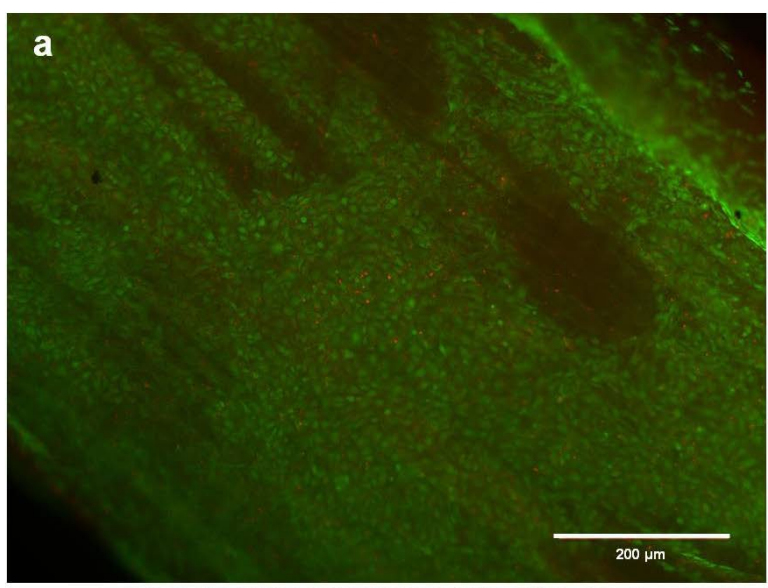

DECELLULARISED MATRIX
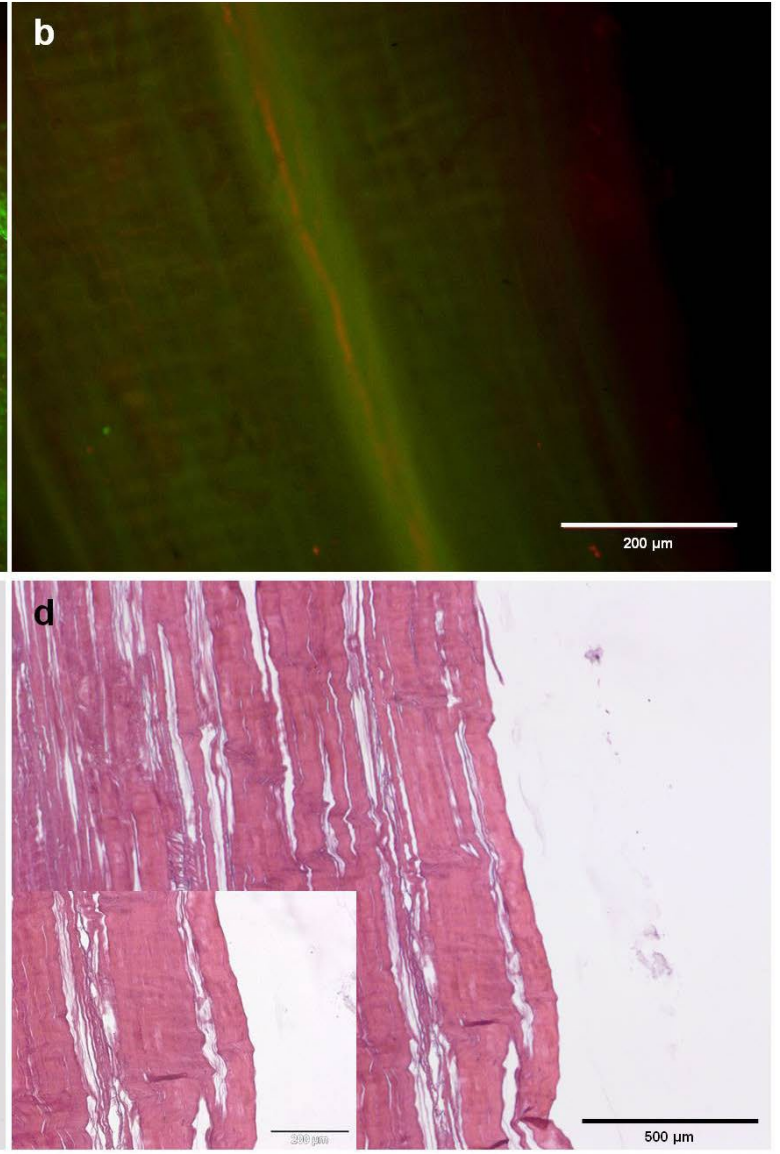

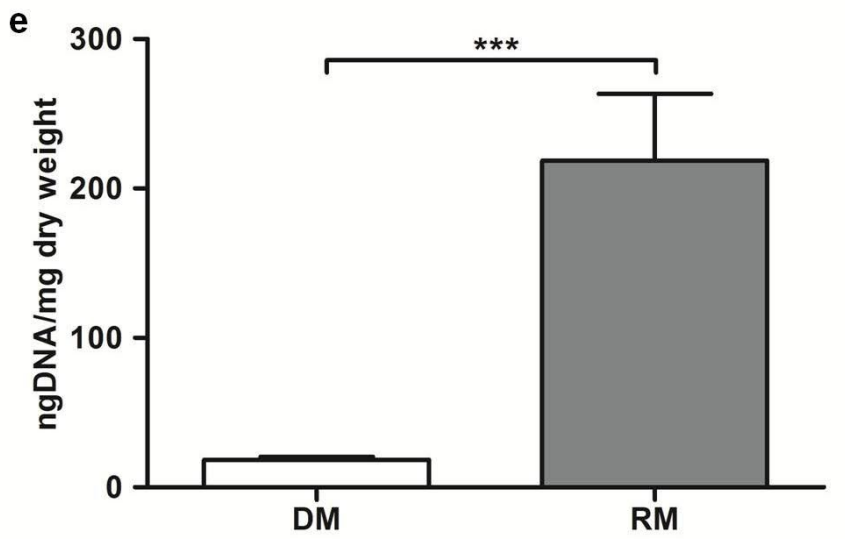

Fig. 7. Reseeded tendon matrix: cell viability, histology and DNA content. Representative panels of the Live \& Dead of the reseeded and decellularised matrix (scale bars: $200 \mu \mathrm{m})(\mathbf{a}, \mathbf{b})$. Representative panels of the haematoxylin and eosin (H\&E) staining of the reseeded and decellularised matrix (scale bars: $500 \mu \mathrm{m}$; small boxes scale bar: $200 \mu \mathrm{m}$ ) (c,d). Effects of NIH-3T3 cell reseeding on the DNA content (ng/mg dry weight) of reseeded matrix (RM) and decellularised matrix (DM). Comparison between groups was analysed with $t$-test. $* * * p<0.001$ (e).

of tendon decellularisation (Cartmell and Dunn, 2000; Cartmell and Dunn, 2004; Youngstrom et al., 2013). Burk et al. (2014) obtained similar DNA data by decellularising the equine tendon with more aggressive detergents, such as the SDS and Triton-X100 (Woods and Gratzer, 2005). Histologically, the increasing concentration of PAA (5\%) disrupted the tissue architecture with a sparsely distributed opening of the collagen fibres, as also supported elsewhere (Deeken et al., 2011; Woon et al., 2011). Conversely, H\&E showed an optimal pattern in tendons decellularised with TBP $+3 \%$ PAA simultaneously with a well-preserved sGAG content. Preserving sGAG content is crucial for both the collagen fibre organisation (Batson et al., 2003) and their water uptake, thus influencing the biomechanical features of the matrix (Badylak, 2002). No other studies combined TBP to PAA to compare our data. However, Youngstrom et al. (2013) found similar values for sGAG content in equine tendons treated with $1 \%$ TBP. Other 
studies that decellularised human flexor tendons with $1 \%$ TBP reported sGAG values two times lower than those obtained in our experiments (Woon et al., 2011; Pridgen et al., 2011). Thus, the optimal cell removal of $\mathrm{TBP}+3 \%$ PAA without affecting the sGAG content made our decellularisation protocol suitable for the generation of a functional acellular tendon matrix. After the removal of the proteoglycans, the total collagen content was lower in all tested decellularisation protocols, particularly in the presence of PAA. (Youngstrom et al., 2013; Youngstrom et al., 2015) and Pridgen et al. (2011) reported similar collagen content results in equine SDFT decellularised with $1 \%$ TBP, despite the reported increase in collagen content of the decellularised tendons compared to the native tissue. This remains unclear considering the well-preserved biochemical composition declared in these studies. In our study, the decreased collagen content of the decellularised samples could be related to the quantification of the total acid-soluble collagen, thus representing a limitation. For this reason, the exact effects of the decellularisation on the total collagen denaturation (soluble and insoluble) and mechanical integrity of tendons need to be defined in future studies. However, the decreased collagen content in our samples did not correlate with the histologic collagen disorganisation, except for the TBP $+5 \%$ PAA, in which a sparsely distributed opening of the collagen fibres was identified. Furthermore, despite the collagen content reduction, all tested decellularisation protocols produced acellular scaffolds with mechanical properties similar to the NT for EM, failure stress and strains. Tendons treated with TBP $+1 \%$ PAA showed a higher EM compared to $\mathrm{TBP}+5 \% \mathrm{PAA}$, thus demonstrating their greater stiffness. Our data strictly correlated with those obtained by (Whitlock et al., 2007) who decellularised chicken flexor tendon with the combination of Triton-X100 and $1.5 \%$ PAA, as well as with data obtained by (Youngstrom et al., 2015) on equine SDFT. The biomechanical results obtained by (Youngstrom et al., 2013; Youngtstrom et al., 2015) on equine tendons are comparable, although lower than the data presented in the current study. This can be explained by the viscoelastic nature of the tendon tissue related to the strain rate used in the tension tests. Indeed, we applied a strain rate twice the value used by (Youngstrom et al., 2013). The high concentrations of PAA (3\% and $5 \%$ ) affected the pure elastic response of the tendon, as evaluated by the stress-relaxation tests. Conversely, the whole viscoelastic behaviour - derived from the stress-strain tests - resulted in a greater EM for $\mathrm{TBP}+1 \%$ PAA, whereas higher concentrations of PAA ( $3 \%$ and $5 \%$ ) restored the viscoelastic response resembling the NT behaviour. This phenomenon might be due to a substantial alteration of the ECM structure related to the permeation induced by $3 \%$ and $5 \%$ PAA. In this study, the use of tendons derived from different horses in terms of age, sex and breeding demonstrated that differences between individual horses did not affect the biomechanical properties, as also demonstrated by others (Thorpe et al., 2010). Finally, the results of cytotoxicity showed that tendons treated with TBP $+1 \%$ PAA and TBP $+3 \%$ PAA have an excellent cytocompatibility. In contrast, the increased percentage of peracetic acid in TBP $+5 \%$
PAA negatively influenced the viability of NIH-3T3 cells, probably due to the presence of greater PAA residuals.

These promising results encouraged the authors to perform a pilot study aimed at evaluating the biocompatibility of the decellularised tendon matrix when statically reseeded with NIH-3T3 fibroblasts. Our results demonstrated good cytocompatibility of the decellularised matrix with TBP $+3 \%$ PAA, as depicted by the seeding efficiency, Live \& Dead assay and histology in RM samples, consistent with another study that used NIH-3T3 cells to repopulate decellularised tendons (Ning et al., 2012). Moreover, the DNA content of our RM samples resembled that described by Woon et al. (2011), in which tendons were treated with $5 \%$ PAA. An interesting fold increase of the collagen content was measured in the RM compared to the DM, reaching values of $7.41 \mu \mathrm{g} / \mathrm{mg}$ dry weight, despite these values not resembling those measured in the NT. Overall, the data demonstrated the enhanced metabolic activity of the fibroblasts reseeded onto the tendon matrix.

In the present study, the decellularisation effectiveness was mainly favourable in tendons treated with TBP $+3 \%$ PAA with respect to the other protocols in terms of cell removal, sGAG preservation, and biomechanical properties. According to our findings, TBP was efficient -conversely to that reported before in another study (Xing et al., 2014) - especially when associated with other agents such as PAA. Using $3 \%$ PAA, instead of commonly used $5 \%$ PAA, facilitated better cell removal together with ameliorating the scaffold porosity while maintaining a matrix structure and composition similar to the NT. The successful combination of TBP $+3 \%$ PAA was also supported in our study, evidenced by good cell reseeding and by the absence of any adverse cytotoxicity.

In accordance with our results, the TBP $+3 \%$ PAA protocol appears to be most suitable for the decellularisation of large tendon grafts, being highly effective in cell removal while maintaining both the native matrix structure and the cytocompatibility of the obtained scaffold.

Our protocol - based on a novel and never before tested combination of decellularisation agents - led to the generation of biocompatible, acellular tendon scaffolds that will be suitable for tendon tissue engineering and hopefully as substitutes in severe tendon damages, like tears and loss of tissue. The next step, before translating this research into clinical practice, could be an optimisation of the host cell reseeding before implantation in preclinical animal models with the goal of replacing tendon defects and regaining a complete activity in patients.

\section{Acknowledgments}

This study was funded by the Italian Ministry of Health (RF- GR-2011-02348899).

The NIH-3T3 murine fibroblasts were kindly provided by Dr S. Previdi (Institute for Pharmacological Research Mario Negri, Milan, Italy). The authors wish to thank Dr. Claire Crowley for the English revision of the manuscript.

The authors declare that there is not conflict of interests regarding the publication of this paper. 


\section{References}

Andarawis-Puri N, Flatow EL, Soslowsky LJ (2015) Tendon basic science: Development, repair, regeneration, and healing. J Orthop Res 33: 780-784.

Badylak SF (2002) The extracellular matrix as a scaffold for tissue reconstruction. Semin Cell Dev Biol 13: $377-383$.

Batson EL, Paramour RJ, Smith TJ, Birch HL, Patterson-Kane JC, Goodship AE (2003) Are the material properties and matrix composition of equine flexor and extensor tendons determined by their functions? Equine Vet J 35: 314-318.

Burk J, Erbe I, Berner D, Kacza J, Kasper C, Pfeiffer B, Winter K, Brehm W (2014) Freeze-thaw cycles enhance decellularization of large tendons. Tissue Eng Part C Methods 20: 276-284.

Cartmell JS, Dunn MG (2000) Effect of chemical treatments on tendon cellularity and mechanical properties. J Biomed Mater Res 49: 134-140.

Cartmell JS, Dunn MG (2004) Development of cellseeded patellar tendon allografts for anterior cruciate ligament reconstruction. Tissue Eng 10: 1065-1075.

Clayton RA, Court-Brown CM(2008) The epidemiology of musculoskeletal tendinous and ligamentous injuries. Injury 39:1338-1344.

Crapo PM, Gilbert TW, Badylak SF (2011) An overview of tissue and whole organ decellularization processes. Biomaterials 32: 3233-3243.

Deeken CR, White AK, Bachman SL, Ramshaw BJ, Cleveland DS, Loy TS, Grant SA (2011) Method of preparing a decellularised porcine tendon using tributyl phosphate. J Biomed Mater Res B Appl Biomater 96: 199-206.

Durgam SS, Stewart AA, Pondenis HC, GutierrezNibeyro SM, Evans RB, Stewart MC (2012) Comparison of equine tendon- and bone marrow-derived cells cultured on tendon matrix with or without insulin-like growth factor-I supplementation. Am J Vet Res 73: 153-161.

Gazdag AR, Lane JM, Glaser D, Forster RA (1995) Alternatives to autogenous bone graft: efficacy and indications. J Am Acad Orthop Surg 3: 1-8.

Garvin J, Qi J, Maloney M, Banes AJ (2003) Novel system for engineering bioartificial tendons and application of mechanical load. Tissue Eng 9: 967-979.

Getgood A, Bollen S (2010) What tissue bankers should know about the use of allograft tendons and cartilage in orthopaedics. Cell Tissue Bank 11: 87-97.

Gilbert TW, Sellaro TL, Badylak SF (2006) Decellularization of tissues and organs. Biomaterials 27: 3675-3683.

Harrison RD, Gratzer PF (2005) Effect of extraction protocols and epidermal growth factor on the cellular repopulation of decellularised anterior cruciate ligament allografts. J Biomed Mater Res A 75: 841-854.

Hudson TW, Zawko S, Deister C, Lundy S, Hu CY, Lee K, Schmidt CE (2004) Optimized acellular nerve graft is immunologically tolerated and supports regeneration. Tissue Eng 10: 1641-1651.
Kemp PD (1994) Peracetic acid sterilization of collagen or collagenous tissue. Patent US5460962, Organogenesis Inc, MA, USA.

Kuo CK, Marturano JE, Tuan RS (2010) Novel strategies in tendon and ligament tissue engineering: Advanced biomaterials and regeneration motifs. Sports Med Arthrosc Rehabil Ther Technol 2: 20.

LovatiAB, Bottagisio M, Moretti M(2016)Decellularised and engineered tendons as biological substitutes: A critical review. Stem Cells Int doi:10.1155/2016/7276150.

Macchiarini P, Jungebluth P, Go T, Asnaghi MA, Rees LE, Cogan TA, Dodson A, Martorell J, Bellini S, Parnigotto PP, Dickinson SC, Hollander AP, Mantero S, Conconi MT, Birchall MA (2008) Clinical transplantation of a tissueengineered airway. Lancet 372: 2023-2030.

Ning LJ, Zhang Y, Chen XH, Luo JC, Li QX, Yang ZM, Qin TW (2012) Preparation and characterization of decellularised tendon slices for tendon tissue engineering. J Biomed Mater Res A 100: 1448-1456.

Pinkowski JL, Rodrigo JJ, Sharkey NA, Vasseur PB (1996) Immune response to nonspecific and altered tissue antigens in soft tissue allografts. Clin Orthop Relat Res 326: $80-85$.

Pridgen BC, Woon CY, Kim MY, Thorfinn J, Lindsey DP, Pham H, Chang J (2011) Flexor tendon tissue engineering: acellularization of human flexor tendons with preservation of biomechanical properties and biocompatibility. Tissue Eng Part C Methods 17: 819-828.

Qin TW, Chen QS, Sun YL, Steinman SP, Amadio PC, An KN, Zhao CF (2012) Mechanical characteristics of native tendon slices for tissue engineering scaffold. J Biomed Mater Res B Appl Biomater 100: 752-758.

Raghavan SS, Woon CY, Kraus A, Megerle K, Choi MS, Pridgen BC, Pham H, Chang J (2012) Human flexor tendon tissue engineering: decellularization of human flexor tendons reduces immunogenicity in vivo. Tissue Eng Part A 18: 796-805.

Schmitt T, Fox PM, Woon CY, Farnebo SJ, Bronstein JA, Behn A, Pham H, Chang J (2013) Human flexor tendon tissue engineering: in vivo effects of stem cell reseeding. Plast Reconstr Surg 132: 567-576.

Sharma P, Maffulli N (2006) Biology of tendon injury: healing, modeling and remodeling. J Musculoskelet Neuronal Interact 6: 181-190.

Shearn JT, Kinneberg KR, Dyment NA, Galloway MT, Kenter K, Wylie C, Butler DL (2011) Tendon tissue engineering: progress, challenges, and translation to the clinic. J Musculoskelet Neuronal Interact 11: 163-173.

Taskiran D, Taskiran E, Yercan H, Kutay FZ (1999) Quantification of total collagen in rabbit tendon by the Sirius Red method. Turk J Med Sci 29: 7-9.

Eastlund T (2006) Bacterial infection transmitted by human tissue allograft transplantation. Cell Tissue Bank 7: 147-166.

Thorpe CT, Stark RJF, Goodship AE, Birch HL (2010) Mechanical properties of the equine superficial digital flexor tendon relate to specific collagen cross-link levels. Equine Vet J 42: 538-543.

Tischer T, Vogt S, Aryee S, Steinhauser E, Adamczyk C, Milz S, Martinek V, Imhoff AB (2007) Tissue engineering of the anterior cruciate ligament: a new method using 
acellularized tendon allografts and autologous fibroblasts. Arch Orthop Trauma Surg 127: 735-741.

Ueda Y, Torrianni MW, Coppin CM, Iwai S, Sawa Y, Matsuda H (2006) Antigen clearing from porcine heart valves with preservation of structural integrity. Int J Artif Organs 29: 781-789.

Whitlock PW, Smith TL, Poehling GG, Shilt JS, Van Dyke M (2007) A naturally derived, cytocompatible, and architecturally optimized scaffold for tendon and ligament regeneration. Biomaterials 28: 4321-4329.

Woods T, Gratzer PF (2005) Effectiveness of three extraction techniques in the development of a decellularised bone-anterior cruciate ligament-bone graft. Biomaterials 26: 7339-7349.

Woon CY, Farnebo S, Schmitt T, Kraus A, Megerle K, Pham H, Yan X, Gambhir SS, Chang J (2012) Human flexor tendon tissue engineering: revitalization of biostatic allograft scaffolds. Tissue Eng Part A 18: 2406-2417.

Woon CY, Pridgen BC, Kraus A, Bari S, Pham H, Chang J (2011) Optimization of human tendon tissue engineering: peracetic acid oxidation for enhanced reseeding of acellularized intrasynovial tendon. Plast Reconstr Surg 127: 1107-1117.

Xing S, Liu C, Xu B, Chen J, Yin D, Zhang C (2014) Effects of various decellularization methods on histological and biomechanical properties of rabbit tendons. Exp Ther Med 8: 628-634.

Yao LW, Wang Q, Zhang L, Zhang C, Zhang B, Zhang YJ, Feng SQ (2015) Patellar tendon autograft versus patellar tendon allograft in anterior cruciate ligament reconstruction: a systematic review and meta-analysis. Eur J Orthop Surg Traumatol 25: 355-365.

Youngstrom DW, Barrett JG, Jose RR, Kaplan DL (2013) Functional characterization of detergentdecellularised equine tendon extracellular matrix for tissue engineering applications. PLoS One 8: e64151.

Youngstrom DW, Rajpar I, Kaplan DL, Barrett JG (2015) A bioreactor system for in vitro tendon differentiation and tendon tissue engineering. J Orthop Res 33: 911-918.

Zhang AZ, Chang J (2003) Tissue engineering of flexor tendons. Clin Plast Surg 30: 565-572.

Zheng MH, Chen J, Kirilak Y, Willers C, Xu J, Wood D (2005) Porcine small intestine submucosa (SIS) is not and acellular collagenous matrix and contains a porcine DNA: possible implications in human implication. J Biomed Mater Res B Appl Biomater 73: 61-67.

\section{Discussion with Reviewers}

Stephen Francis Badylak: Can the authors please explain more as to why they chose to use TBP as the principal detergent for decellularisation?

Authors: Detergents employed to decellularise tissues are typically classified into ionic, non-ionic, and zwitterionic, as widely described in our previously published review (Lovati et al., 2016). The efficacy of non-ionic (Triton $\mathrm{X}-100$ ), ionic (SDS) and zwitterionic (TBP) detergents to obtain a complete tendon decellularisation was compared in detail. TBP and SDS are considered the most efficacious reagents to obtain an adequate decellularised tendon matrix, while preserving the mechanical properties of the native tendon. Specifically, TBP has been established to be more effective to decellularise dense tissues such as tendon than other detergents (Triton X-100 and SDS) with varying effects on retention of extracellular matrix component, histologic pattern and native mechanical properties (Cartmell and Dunn, 2000; Deeken et al., 2011; Crapo et al., 2011). Furthermore, thanks to disinfectant and bacteriostatic properties, TBP has been successfully applied in scaffold preparation for skin grafts, heart valves, blood vessels, tendons, ligaments and cartilage (Crapo et al., 2011; Deeken et al., 2011). Otherwise, despite an excellent decellularisation of tissues, it has also been demonstrated that the use of Triton X-100 and SDS, associated or not, clearly damaged the glycosaminoglycan, increased the collagen tensile strength (Woods et al., 2005), exhibited numerous cell debris and mild collagen damages (Cartmell and Dunn, 2000; Cartmell and Dunn, 2004). Again, the ionic detergents (SDS) destroy the cell membrane, denature proteins, thus affecting the collagen structure and are associated with cytotoxicity of detergent residuals. Finally, the non-ionic detergents (Triton X-100) affect the lipid-lipid and lipid-protein interaction, and severely remove glycosaminoglycans from the extracellular matrix. According to this, the zwitterionic TBP is recommended to decellularise tendons thanks to its capability to completely eliminate the cell nuclei, while maintaining the extracellular matrix structure. Moreover, the capability of TBP to inactivate viruses is crucial in reducing the risk for disease transmission in xenogeneic tissue transplantation.

Stephen Francis Badylak: Why are equine tendons preferred $v s$. tendons from other mammals? The authors cite supply - but arguably porcine tendons would provide a better supply.

Authors: Xenografts derive from different animal species (bovine, porcine and equine) and, after extensive processing techniques; they provide biocompatible products for reconstructive surgery of several organs and tissues. As mentioned in the manuscript, some advantages in using large animals as a source of tissues are their easy supply at the slaughterhouse, and the large amount of retrievable materials. In particular, tendons have proper dimensions and biomechanical characteristics similar to humans. Despite the apparent advantages in using porcine or bovine as donor species, these retain a great variety of transmittable pathogens to humans (Borie et al., 1998). In particular, the bovine spongiform encephalopathy (BSE) and porcine endogenous retroviruses (PERVs) represent the most dangerous transmissible diseases. Specifically, infections that cause BSE in the bovine species, when transplanted into humans, they can cause the CreutzfeldtJakob disease (CJD) and its variant (vCJD). Otherwise, pigs are the main source of tissues and organs already used in clinics. However, pigs retain many active or latent viruses embedded in their cell genome such as PERV causing an AIDS-like disease in the immunosuppressed human transplant recipient. In recent years, another infection that humans can acquire from pigs is the lethal Ebola virus 
(EBOV) (Singh et al., 2013). In this scenario, the use of equine xenografts has become popular. Indeed, equine xenografts are becoming even more used for reconstructive surgery (Lovati et al., 2016; Chen et al., 2009; Longo et al., 2010), also due to a significantly inferior presence and often geographically limited zoonotic diseases (Weese 2002). However, research on risk on disease transmission through equine is still under investigation.

Stephen Francis Badylak: Why does the elastic modulus increase with TBP $+1 \%$ PAA group? What is the hypothesis for this result?

Authors: The exact effect of the TBP, PAA and their combinations used in our decellularisation protocols and found in the literature is still not fully understood (Crapo et al., 2011). Our hypothesis for these results in mechanical testing is that a low concentration of PAA, such as $1 \%$, could have altered the ECM structure by determining some reticulations in the protein structure and affecting the interaction among its components, thus inducing the increase of the elastic modulus, as also sustained by others (Woon et al., 2011). Similar biomechanical results have been also reported by other studies on the decellularisation of intestine submucosa (Syed et al., 2014). Differently, the greater permeability of the ECM structure as well as a probable increased fibre interspaces induced by higher concentrations of PAA, such as $3 \%$ and $5 \%$, could be responsible for the restoration of the elastic modulus to levels comparable with the native one. In fact, other groups observed increased fibre interspaces in human patellar tendon allografts treated with PAA (Lomas et al., (2004).

Stephen Francis Badylak: The investigators utilised 3T3 fibroblasts as an indicator of cellular compatibility. 3T3 fibroblasts are very hardy cells and will grow on almost any surface. This is a poor cell choice to determine whether or not the decellularised tissues are cytocompatible. Without conducting additional experiments, at a minimum, a discussion of this point should be included.

Authors: International standards for medical devices (ISO 10993) have been published by ISO in 1992 declaring that new medical devices must go through in vitro and in vivo biocompatibility tests (cytotoxicity, sensitisation, intradermal irritation, acute systemic toxicity, etc.) before entering into human clinical trials. Among the biocompatibility tests, the cytotoxicity is chosen as the leading test thanks to its ease, rapidity and high sensitivity. It is based on the analysis of cell growth, reproduction and morphological effects of the medical devices ( $\mathrm{Li}$ et al., 2015). Commonly, in vitro basal cytotoxicity and cytocompatibility can be performed in different primary cells, as well as in a variety of permanent cell lines. However, established rodent cell lines, like mouse fibroblast NIH-3T3, are recommended because they assure in vitro reproducibility, in vivo prediction and a corroborate background of historical data. Moreover, NIH-3T3 cells, having a population doubling time $\leq 30 \mathrm{~h}$, are capable of active division, during which chemicals exercise their toxicity. Therefore, the main advantages in using these cells are a short-term detection of cytocompatibility, high reproducibility, and easy availability as a commercial product. Differently, primary cells from humans are a highly variable source and greatly differentiated as well as undifferentiated cells may not give the best prediction of acute toxicity (Ekwall et al., 1998). Finally, in our case, the use of fibroblasts can resemble the fibroblast-like cells residing within the tendon structure. Indeed, NIH-3T3 cells secrete typical tendon ECM molecules, such as collagen type I, III and proteoglycans, and more interestingly they proliferate faster than tendon fibroblasts (Cooper et al., 2014; Ning et al., 2012). Furthermore, several studies in the field of tendon decellularisation employed dermal fibroblasts to repopulate decellularised matrices. In particular, some of them used rabbit fibroblasts (Tischer et al., 2007; Tischer et al., 2010; Angelidis et al., 2010) or human fibroblasts (Woon et al., 2011; Raghavan et al., 2012; Pridgen et al., 2011; Cartmell and Dunn 2004) that are not well-characterised cells as the NIH-3T3. However, because of the variability of the in vivo environment and of the implant-host interactions, a homogeneous analysis to test both the cytocompatibility and the cytotoxicity has not been established so far. Our cytocompatibility test needed to be a proof of concept of cell adhesion and viability onto the decellularised matrix. Thus, following this study, further experiments will be performed to evaluate the capability of more delicate cells (MSCs or tenocytes) in growing onto these decellularised tissues.

Walter Brehm: Why does the tendon appear so damaged? Authors: The authors hypothesised that the damaged tendon structure of the decellularised matrix (DM) in Fig. $7 \mathbf{c}, \mathbf{d}$ could be related to the different plane of histologic sectioning. Indeed, it must be taken into account that the histologic sections reported in Fig. 7c,d were cut along the sagittal plane with respect to the tendon anatomy, in order to identify the presence of cells and their matrix onto the tendon surface. Differently, the histologic sections presented in Fig. 1 and 2 were cut along the coronal plane to be correctly compared to other similar studies. Thus, it is misleading to compare the homogeneous histologic texture reported in Fig. 1 and 2 to the damaged texture in Fig. 7 c,d. Moreover, the authors also hypothesised that the immersion of the small pieces of DM $(5 \mathrm{~mm} \times$ $5 \mathrm{~mm} \times 3 \mathrm{~mm}$ ) in the culture medium for $7 \mathrm{~d}$ could have damaged the DM structure. In fact, the DM proteoglycans were affected not only by the decellularisation process, but also by the isotonic culture medium (Hunziker and Graber 1986), determining an increased opening of the collagen fibres. Overall, the combination of proteoglycan decrease, the small dimensions of the samples and several days in contact with the culture medium at $37^{\circ} \mathrm{C}$ can severely affect the cohesiveness of the tendon structure. For this reason, the fibres appeared more distant from each other.

Walter Brehm: Why is there a layer of unstructured connective tissue on the tendon in Fig. 7c but not in Fig. 7d? According to my experience, this layer was not synthesised by the cells but is derived from loose tendon fibres.

Authors: The layer of unstructured connective tissue onto the tendon matrix in Fig. $7 \mathbf{c}$ is determined by the fibroblast seeded on the surface of the decellularised matrix (DM), thus consisting in the reseeded matrix 
(RM). Differently, in Fig. 7d, this layer was not present because this is the DM that was not reseeded with any cells. In Fig. 7c, the connective tissue layer appeared to be synthesised by fibroblasts in close contact with the tendon matrix. However, the newly formed connective tissue was completely disorganised. Indeed, in the absence of mechanical stimuli, as commonly happens in native tendons during loading, the loaded fibroblasts were largely oriented randomly in space, round-shaped and not aligned along the collagen fibre direction. This phenomenon is probably related to the absence of any mechanical stimuli or dynamic culture, in fact, our reseeding and culture of the decellularised matrix was performed under static conditions. As demonstrated in several similar studies and widely investigated in our previously published review (Lovati et al., 2016), the static culture had a significant influence in impeding both the cell penetration within the tendon fibres and the cell orientation along the collagen fibres.

Walter Brehm: Why do no cells migrate into the tissue, and why do all cells have a round morphology? Normally, they should be oriented between the tendon fibres.

Authors: In the recent literature (Lovati et al., 2016), similar results in terms of absence of cell penetration and presence of rounded cells were described by several studies, in which the decellularised tendon matrices were seeded and cultured under static conditions (Cartmell and Dunn 2004; Ning et al., 2012; Woon et al., 2011; Raghavan et al., 2012; Pridgen et al., 2011; Burk et al., 2014; Durgam et al., 2012). Different results, in terms of cell penetration within the decellularised matrix, were obtained by the authors that performed dynamic culture, a direct cell injection within the matrix fibres (Tischer et al., 2007), or matrix sonication. Other authors, despite performing a cell injection within the matrix fibres, described a cell distribution merely on the matrix surface (see in Lovati et al., 2016). Only Youngstrom et al. and Youngstrom et al. (2013 \& 2015), despite better results obtained in dynamic conditions compared to static, declared a good cell infiltration in the static condition too. In particular, Youngstrom and colleagues performed the decellularisation by using a more aggressive detergent, such as the SDS. In the future, the authors of the current study are going to improve the decellularised matrix cell reseeding and culture under dynamic conditions by using a specifically custommade bioreactor in order to overcome these limitations in terms of cell colonisation of the tendon matrix core and correct deposition of newly formed connective tissue following the physiological orientation of the tendon fibres.

\section{Additional References}

Angelidis IK, Thorfinn J, Connolly ID, Lindsey D, Pham HM, Chang J (2010) Tissue engineering of flexor tendons: the effect of a tissue bioreactor on adipoderived stem cell-seeded and fibroblast-seeded tendon constructs. J Hand Surg Am 35: 1466-1472.

Borie DC, Cramer DV, Phan-Thanh L, Vaillant JC, Bequet JL, Makowka L, Hannoun L (1998) Microbiological hazards related to xenotransplantation of porcine organs into man. Infect Control Hosp Epidemiol 19: 355-365.

Cartmell JS, Dunn MG (2000) Effect of chemical treatments on tendon cellularity and mechanical properties. J Biomed Mater Res 49: 134-140.

Cartmell JS, Dunn MG (2004) Development of cellseeded patellar tendon allografts for anterior cruciate ligament reconstruction. Tissue Eng 10: 1065-1075.

Chen J, Xu J, Wang A, Zheng M (2009) Scaffolds for tendon and ligament repair: review of the efficacy of commercial products. Expert Rev Med Devices 6: 61-73.

Cooper JO, Bumgardner JD, Cole JA, Smith RA, Haggard WO (2014) Co-cultured tissue-specific scaffolds for tendon/bone interface engineering. J Tissue Eng 5: doi: 10.1177/2041731414542294.

Crapo PM, Gilbert TW, Badylak SF (2011) An overview of tissue and whole organ decellularization processes. Biomaterials 32: 3233-3243.

Deeken CR, White AK, Bachman SL, Ramshaw BJ, Cleveland DS, Loy TS, Grant SA (2011) Method of preparing a decellularised porcine tendon using tributyl phosphate. J Biomed Mater Res B Appl Biomater 96: 199-206.

Ekwall B, Clemedson C, Crafoord B, Ekwall B, Hallander S, Walum E, Bondesson I (1998) MEIC Evaluation of Acute Systemic Toxicity: Part V. Rodent and Human Toxicity Data for the 50 Reference Chemicals 26 Suppl 2: 571-616.

Hunziker EB, Graber W (1986) Differential extraction of proteoglycans from cartilage tissue matrix compartments in isotonic buffer salt solutions and commercial tissueculture media. J Histochem Cytochem. 34: 1149-1153.

Li W, Zhou J, Xu Y (2015) Study of the in vitro cytotoxicity testing of medical devices. Biomed Rep 3: 617-620.

Lomas RJ, Jennings LM, Fisher J, Kearney JN (2004) Effects of a peracetic acid disinfection protocol on the biocompatibility and biomechanical properties of human patellar tendon allografts. Cell Tissue Bank 5: 149-160.

Longo UG, Lamberti A, Maffulli N, Denaro V (2010) Tendon augmentation grafts: a systematic review. Br Med Bull 94: 165-188.

Lovati AB, Bottagisio M, Moretti M (2016) Decellularised and engineered tendons as biological substitutes: A critical review. Stem Cells Int 2016: doi:10.1155/2016/7276150.

Ning LJ, Zhang Y, Chen XH, Luo JC, Li QX, Yang ZM, Qin TW (2012) Preparation and characterization of decellularised tendon slices for tendon tissue engineering. J Biomed Mater Res A 100: 1448-1456.

Pridgen BC, Woon CY, Kim MY, Thorfinn J, Lindsey DP, Pham H, Chang J (2011) Flexor tendon tissue engineering: acellularization of human flexor tendons with preservation of biomechanical properties and biocompatibility. Tissue Eng Part C Methods 17: 819-828.

Raghavan SS, Woon CY, Kraus A, Megerle K, Choi MS, Pridgen BC, Pham H, Chang J (2012) Human flexor tendon tissue engineering: decellularization of human flexor tendons reduces immunogenicity in vivo. Tissue Eng Part A 18: 796-805. 
Singh R, Mahesh L, Shukla S (2013) Infections Resulting from Bone Grafting Biomaterials. Int J Oral Implantol Clin Res 4: 68-71.

Syed O, Walters NJ, Day RM, Kim HW, Knowles JC (2014) Evaluation of decellularization protocols for production of tubular small intestine submucosa scaffolds for use in oesophageal tissue engineering. Acta Biomater 10: $5043-5054$.

Tischer T, Vogt S, Aryee S, Steinhauser E, Adamczyk C, Milz S, Martinek V, Imhoff AB (2007). Tissue engineering of the anterior cruciate ligament: a new method using acellularized tendon allografts and autologous fibroblasts. Arch Orthop Trauma Surg 127: 735-741.

Tischer T, Aryee S, Wexel G, Steinhauser E, Adamczyk C, Eichhorn S, Milz S, Martinek V, Gänsbacher B, Imhoff $A B$, Vogt $S$ (2010) Tissue engineering of the anterior cruciate ligament-sodium dodecyl sulphate- acellularized and revitalized tendons are inferior to native tendons. Tissue Eng Part A 16: 1031-1040.
Weese JS, (2002) A review of equine zoonotic diseases: risks in veterinary medicine. Proceedings of the Annual Convention of the AAEP 48: 362-369.

Woods T, Gratzer PF (2005) Effectiveness of three extraction techniques in the development of a decellularised bone-anterior cruciate ligament-bone graft. Biomaterials 26: 7339-7349.

Woon CY, Pridgen BC, Kraus A, Bari S, Pham H, Chang J (2011) Optimization of human tendon tissue engineering: peracetic acid oxidation for enhanced reseeding of acellularized intrasynovial tendon. Plast Reconstr Surg 127: 1107-1117.

Youngstrom DW, Barrett JG, Jose RR, Kaplan DL (2013) Functional characterization of detergentdecellularised equine tendon extracellular matrix for tissue engineering applications. PLoS One 8: e64151.

Editor's note: The Scientific Editor responsible for this paper was Juerg Gasser. 